\title{
Study on Thermal Behavior of Some Biocompatible and Biodegradable Materials Based on Plasticized PLA, Chitosan, and Rosemary Ethanolic Extract
}

\author{
Cornelia Vasile $\mathbb{B D}^{1}{ }^{1}$ Niță Tudorachi $\mathbb{D}^{1},{ }^{1}$ Traian Zaharescu, ${ }^{2}$ Raluca Nicoleta Darie-Nita $\left(\mathbb{D},{ }^{1}\right.$ \\ and Catalina Natalia Cheaburu-Yilmaz $\mathbb{D D}^{1}$ \\ ${ }^{1}$ Department of Physical Chemistry of Polymers, "Petru Poni” Institute of Macromolecular Chemistry, 41A Gr. Ghica Voda Alley,
700487 Iasi, Romania
${ }^{2}$ National Institute for Electrical Engineering (INCDIE ICPE CA), 313 Splaiul Unirii, P.O. Box 149, 030138 Bucharest, Romania \\ Correspondence should be addressed to Cornelia Vasile; cvasile@icmpp.ro and Raluca Nicoleta Darie-Nita; darier@icmpp.ro
}

Received 25 March 2020; Accepted 19 May 2020; Published 15 July 2020

Guest Editor: Ai-Min Wu

Copyright (C) 2020 Cornelia Vasile et al. This is an open access article distributed under the Creative Commons Attribution License, which permits unrestricted use, distribution, and reproduction in any medium, provided the original work is properly cited.

\begin{abstract}
Thermal characterization of some multifunctional environmentally friendly materials based on plasticized poly (lactic acid) (PLA)/chitosan (CS) and rosemary extract (R) previously obtained is presented. Differential scanning calorimetry (DSC) associated with other complex investigations such as chemiluminescence and coupled thermogravimetry (TG)/Fouriertransform infrared spectroscopy (FT-IR)/mass spectroscopy (MS) was performed in order to test both the thermal behavior and the biocomposition-property relationship. It was established that the rosemary ethanolic extract offers an efficient protection against thermoxidative degradation to the new developed plasticized PLA-based biocomposites which show good thermal properties, being suitable for both medical and food packaging applications.
\end{abstract}

\section{Introduction}

The green and biodegradable composites are interesting materials for environmental-friendly food packaging and biomedical fields.

However, biodegradable polymers cannot be widely used because of their high prices, low thermostability, and mechanical properties [1]. Among the biodegradable polymers, poly (lactic acid) (PLA) is a reliable alternative, being a biobased material with good clarity, high strength, and moderate barrier properties. PLA has biodegradability and annually renewable availability and can be processed by standard melt processes such as injection moulding, film blowing, or melt spinning [1]. Industrial implementation of PLA-based materials is impeded due to its low thermal stability, sensitivity to hydrolysis, low crystallization rate, and high brittleness. PLA is degraded during thermal processing or under hydrolytic conditions, resulting in rapid reduction of molecular weight that affects the final properties of the materials $[2,3]$. Most reported data indicates that its thermal degradation occurs either by a random main-chain scission reaction [4], as well as by depolymerization, oxidative degradation, and transesterification reactions $[5,6]$ The reaction was found under these experimental conditions to be of first order with an activation energy of 94.0 and $105.3 \mathrm{~kJ} /$ mole and preexponential factor $6.43 \times 10^{5}$ and $1.91 \times 10^{6} \mathrm{~s}^{-1}$, respectively [7]. Moreover, reactive end groups, residual catalyst, unreacted starting monomer, and other impurities may influence the PLA thermal degradation [5] Many efforts were made to suppress polymer degradation in the melt [8] or to accelerate degradation of worn-out PLA-based products/waste. Its serious drawbacks consist of low deformation at break but with high modulus and low heat resistance. PLA has very low crystallinity, leading to inferior thermostability problems during its long service life [9-12]. Therefore, some properties required to be improved. Different solutions have been tested to overcome them making PLA suitable for competing against oil derivative polymers. PLA needs to be modified to improve 
its processing or material properties. Several heat resistance modification methods have been applied, such as nucleating agent addition, fiber reinforcement, compounding, blending, stereoisomer complexation, copolymerization, chemical modification, and additive incorporation $[13,14]$.

The additives (nucleating agents, natural additives, stabilizers, etc.) when used in a concentration range between 1 and $5 \mathrm{wt} \%$ have no effects on film transparency. At loadings between 20 and $30 \mathrm{wt} \%$, the filler acts as a nucleating agent promoting the development of crystallinity.

The most practical method to obtain soft, flexible, and ductile characteristics and inherent thermal stability of PLA is its blending with various plasticizers (e.g., esters, tributyl ortho-acetyl citrate, tributyl citrate, triacetin (triglyceride 1,2,3-triacetoxypropane), polyethylene glycol (PEG), di (ethyl-hexyl phthalate, tricresyl phosphate or triisooctyl trimellitate, and butyl benzoate) [15-17]. It was found that the plasticized PLA with tributyl o-acetyl citrate (ATBC) reduced brittlenes of PLA; the sheets and films obtained from plasticized PLA/CS biocomposites have satisfactory transparence and mechanical and improved thermal properties [18-20]. Good results were also obtained when plastifying PLA by using PLA oligomer, l-lactide, poly (ethylene glycol), and epoxidized soybean oil. Epoxidized soybean oil significantly increased the elongation at break and reduced the glass transition temperature because of the changes in chain mobility [21]. Some blends (PLA/ATBC, PLA/polyester bioplasticizer as LAPOL108, and PLA/tributyl citrate plasticizer TBC) present an increase in crystallinity degree value. The same changes are found for the PLA/PEG blend in accordance with the results given in literature [22].

The PLA formulations offering satisfactory properties of materials can be accomplished by the addition of various additives able to improve the features of basic polymer.

Chitosan (CS) biopolymer exhibits outstanding properties as biocompatibility and biodegradability being a relevant candidate in the field of biomaterials [23] It was approved by the Food and Drug Administration (FDA) for use in wound dressings [24] and food packaging. The development of new biodegradable packaging materials, such as PLA/CS films, could be an interesting alternative to change PLA properties.

Some naturally occurring compounds can delay oxidative deterioration of contacting food products, maintaining their nutritional quality and also improving oxidative stability of other types of materials. As an example, the natural antioxidants from a certain extract from herbs and spices such as rosmarinic acid from rosemary, thymol from oregano, eugenol from clove, and curcumin from turmeric are rich in polyphenolic compounds that provide long-term oxidative stability as well as offer additional health benefits [19, 25]. High antioxidative capacity and phenolics of herbs and spices could potentially substitute synthetic antioxidants such as butylated hydroxytoluene (BHT), butylated hydroxyanisole (BHA), propyl gallate (PG), octyl gallate, and tert-butylated hydroquinone (TBHQ) in the food system. Moreover, the synthetic antioxidants are thermally unstable and decompose at higher temperatures. In the food industry, widely apply cooking methods such as baking, frying, boiling, and roasting use high temperature that may also degrade herbs and spices and diminish their antioxidative capacity. However, these kinds of natural additives have been scarcely studied [26]. The impact of temperature on total antioxidant capacity of various herbs and spices such as cinnamon, clove, nutmeg, mace, oregano, rosemary, sage, and turmeric was followed. Tomaino and others [27] and Khatun and others [28] evaluated the antioxidant activity of spices of ethanol extract of cloves, cinnamon, nutmeg, mace, and turmeric, and they found that the thermal treatments may increase the antioxidant activity by releasing bound antioxidants or by the formation of new compounds with antioxidant properties. It was found that the ethanol extracts of cloves, cinnamon, nutmeg, mace, and turmeric showed to have antioxidative potential such as DPPH radical-scavenging and peroxy radicalscavenging activities. This was also proved by other authors by heating several essential oils (clove, cinnamon, nutmeg, oregano, mace, tumeric, etc.) [26].

The degradation rates can be controlled by blending PLA with additives, inorganic fillers, and nanoparticles, although other factors determine degradation of PLA-based materials such as manufacture procedures, outer service, and environmental conditions. The control of the PLA degradation is mandatory for both medical applications and for the plastic industry. The mechanism as well as the rate of degradation reaction for PLA-based materials seems to be affected by a wide variety of compositional and property variables. Therefore, the assessment of the thermal behavior of all kinds of new materials with application in medical and food industry field is an important requirement. To obtain PLA-based materials with special properties such as antioxidant and antimicrobial activities and biocompatibility, with wide applications both in medical field and food preservation, much complex formulations should be used. Incorporation of CS and rosemary extract into plasticized PLA led to materials possessing such multifunctional properties [29].

The thermal behavior of some biocomposites based on plasticized PLA containing CS and rosemary ethanolic extract is presented in this study by applying differential scanning calorimetry (DSC), chemiluminescence method (CL), and coupled thermogravimetry (TG)/Fourier-transform infrared spectroscopy (FT-IR)/mass spectroscopy (MS). By applying these coupled methods of investigation, the composition-property relationship for the developed biocomposites was establish. It has been found that the addition of CS shifted the glass transition temperature $\left(T_{\mathrm{g}}\right)$ to slightly higher values while the cold crystallization temperature $\left(T_{\mathrm{cc}}\right)$ of PLA-based biocomposites to lower values. It was explained by the effect of CS which is able to promote the crystallization of PLA, leading to an increased crystallization degree of the biocomposites in respect with that of plasticized PLA, because the melting heat takes higher values for biocomposites with increased CS content. The results of the chemiluminescence study proved that the rosemary ethanolic extract is a good stabilizer for thermoxidative degradation of PLA. The PLA/PEG/6CS and PLA/PEG/CS/R biocomposites show the highest characteristic temperature values and apparent activation energy of decomposition. It was concluded that the plasticized PLA/CS/R materials show good thermal properties and most of thermal degradation 
products are nontoxic being recommended for both medical and food packaging applications.

\section{Experimental}

2.1. Materials. Poly (lactic acid) (PLA) (trade name: PLA 2002D) from NatureWorks LLC, UK, with a melt flow index of $5-7 \mathrm{~g} / 10 \mathrm{~min}$ (conditions, $210^{\circ} \mathrm{C} / 2.16 \mathrm{~kg}$ ) and a content of $96 \%$ L-lactide and isomer D 4\%, was used. Average molecular weight determined by GPC was $4475 \mathrm{kDa}$. According to the literature data, it has a density of $1.25 \mathrm{~g} / \mathrm{cm}^{3}$, melting point of $152^{\circ} \mathrm{C}$, and glass transition temperature of $58^{\circ} \mathrm{C}$; the crystallinity depends on isomer content and thermal history; water permeability at $25^{\circ} \mathrm{C}$ is $172 \mathrm{~g} / \mathrm{m}^{2}$ per day; and percentage of biodegradation/mineralization is $100 \%$.

Chitosan (CS) with $200-800 \mathrm{cP}$ viscosity in $1 \%$ acetic acid, $75-85 \%$ deacetylation degree, and MW $=190-300 \mathrm{kDa}$ was provided and used as received from Sigma-Aldrich.

Rosemary extract (R) in powder form was obtained following a previously reported procedure by the solvent extraction method in a Soxhlet unit [30]. Rosemary leaves were collected from local farms, dried at ambient temperature, and subsequently milled (Laboratory of Radiation Chemistry, INCDIE-ICPE CA, Bucharest, Romania). Ethanol was used as an extraction solvent. After collection of the rosemary extract in an ethanol solution, the powder was separated by precipitation induced by the addition of water. The insoluble material was filtered and washed with acetone until it was dried. The extract was further dried under vacuum at ambient temperature. A greenish-yellow fine powder was obtained and stored in desiccators to avoid the absorption of moisture. Its main components are carnosol and carnosic acid which show in the UV spectra a $\lambda_{\max }$ around 283 and $246 \mathrm{~nm}$, while for rosmarinic acid, absorbances at 230,270, 280, and $330 \mathrm{~nm}$ were obtained [31]. Its amount of total phenols was of $112.5 \mathrm{mg}$ GAE (gallic acid equivalent)/g dw (dry weight), while the total flavonoid content was of 261.5 (mg QE (quercetin equivalents)/g dw) [25]. The present study intended to evidence its effect on plasticized PLA together with chitosan on the thermal behavior of some biocomposites.

Poly (ethylene glycol) (PEG) BioUltra 4.000 (SigmaAldrich) was used as plasticizer.

PLA-based biocomposites were prepared using different amounts of chitosan or/and rosemary extract by incorporating them into PLA matrix in a melt state using a fully automated laboratory Brabender station (Brabender ${ }^{\circledR}$ Plasti-Corder ${ }^{\circledR}$ Lab-Station EC, Brabender GmbH \& Co. KG, Duisburg, Germany). The processing temperature was $165^{\circ} \mathrm{C}$ for $10 \mathrm{~min}$, at a rotor speed of $60 \mathrm{rpm}$. The PLA/PEG/rosemary/chitosan biocomposite systems prepared contained $20 \mathrm{wt} \%$ PEG, 3 and $6 \mathrm{wt} \% \mathrm{CS}$, and $0.5 \mathrm{wt} \%$ rosemary ethanolic extract (R). More details on characteristics/properties of the biocomposites studied and their preparation are found in a previous paper [29].

\subsection{Investigation Methods}

2.2.1. Differential Scanning Calorimetry (DSC). A TA Instrument Q20 Differential Scanning Calorimeter (New Castle, DE, USA) was employed for the thermal characterization, sample amount being of $\sim 10 \mathrm{mg}$. All of the samples were cooled down to $0^{\circ} \mathrm{C}$ and heated up to $250^{\circ} \mathrm{C}$, so below and above materials expected glass transition and melting temperature. After first heating run, all samples were kept for $2 \mathrm{~min}$ at $250^{\circ} \mathrm{C}$ and then cooled down to $0^{\circ} \mathrm{C}$ with a cooling rate of $5^{\circ} \mathrm{C} / \mathrm{min}$ and heated again for a second run up to $250^{\circ} \mathrm{C}$ with a heating rate of $10^{\circ} \mathrm{C} / \mathrm{min}$. An empty crucible was used as reference. All measurements were performed under nitrogen atmosphere. The degree of crystallinity $\left(X_{c}\right)$ of the PLA and its composites was calculated by dividing the melting enthalpy of the sample by $\Delta H^{\circ}{ }_{\mathrm{m}}=93.7 \mathrm{~J} / \mathrm{g}[32$, 33], which is equilibrium enthalpy of a PLA sample with $100 \%$ crystallinity. An overall accuracy of $\pm 0.5^{\circ} \mathrm{C}$ in temperature and $\pm 1 \%$ in enthalpy was estimated. The final results are the average of three recordings.

2.2.2. Chemiluminescence (CL). The LUMIPOL 3 unit (SAS, Bratislava, Slovakia) chemiluminescence spectrometer was used in the recording of nonisothermal emission intensity dependencies on temperature on film samples with small weights not exceeding $5 \mathrm{mg}$. The selected temperature range starts from room temperature being ended at $250^{\circ} \mathrm{C}$. The measured temperatures had a low error $\left( \pm 0.5^{\circ} \mathrm{C}\right)$. Heating rates were $2,3.7,5$, and $10^{\circ} \mathrm{C} \mathrm{min}^{-1}$. CL determinations were carried out in air under static conditions. The CL intensity values are normalized to sample mass for their reliable comparison. The activation energy of the oxidation process was determined by the Kissinger method [34-37].

\subsubsection{Coupled Thermogravimetry/Fourier-Transform Infrared} Spectroscopy/Mass Spectroscopy (TG/FTIR/MS). Thermal degradation was followed by simultaneous TG/FTIR/MS thermal analyses. The thermal study was performed on a STA 449 F1 Jupiter apparatus (Netzsch STA 44F1, Germany). The heating program started from $30^{\circ} \mathrm{C}$ up to $600^{\circ} \mathrm{C}$ at a $10^{\circ} \mathrm{C} \mathrm{min}^{-1}$ heating rate, under nitrogen as a purge and protective gas for a flow rate of $40 \mathrm{ml} / \mathrm{min}$. The temperature reproducibility of TG was $\pm 2^{\circ} \mathrm{C}$, and the nonvolatile fraction was $\pm 3 \%$. The thermobalance was coupled with a Vertex 70 IR spectrophotometer and an Aeolos QMS 403C mass spectrometer (Netzsch, Germany) for in situ recording of the spectral characteristics of the degradation gaseous products. For each recording, $12-15 \mathrm{mg}$ of sample was placed in $\mathrm{Al}_{2} \mathrm{O}_{3}$ crucible. Temperature calibration was done with standard indium, zinc, tin, bismuth, and aluminum of $99.99 \%$ purity. Volatile degradation products in a temperature-controlled environment were directly transferred both to an electron impact ion source of a mass spectrometer QMS 403C Aeolos (Netzsch, Germany) type and to an infrared (FTIR) spectrometer (Bruker, Germany), via a heated capillary tube, and analyzed by in situ vapor phase FTIR. Transfer of the degradation gaseous products was realized through two isothermal lines.

\section{Results and Discussion}

3.1. DSC Results. DSC measurements on plasticized PLAbased biocomposites were carried out both by heating and cooling. The thermal properties of these materials, such as 
glass transition temperature $\left(T_{\mathrm{g}}\right)$, crystallization temperature $\left(T_{\mathrm{c}}\right)$, cold crystallization temperature $\left(T_{\mathrm{cc}}\right)$, melting temperature $\left(T_{\mathrm{m}}\right)$, crystallization enthalpy $\left(\Delta H_{\mathrm{c}}\right)$, melting enthalpy $\left(\Delta H_{\mathrm{m}}\right)$, and crystallinity degree $\left(X_{\mathrm{c}}\right)$, were evaluated. The DSC curves of the studied biocomposites containing CS and $0.5 \% \mathrm{R}$ comparatively with those of PEG-plasticized PLA are presented in Figure 1, and the results are summarized in Table 1.

In the DSC curves, glass transition and melting processes were clearly evidenced. In the $45-65^{\circ} \mathrm{C}$ range, both glass transition of PLA and melting of PEG 4000 [38] can occur, the DSC curves showing two processes with the second one at about $60^{\circ} \mathrm{C}$ for most biocomposites with the exception of PLA/PEG/6CS/0.5R which show only one temperature indicating a good dispersion of components in a PLA-based matrix. The first peak is placed at lower temperature around $50^{\circ} \mathrm{C}$ and could be assigned to PEG melting taking into consideration literature data. The intense crystallization peaks have been found for PEG of 4000 and 20,000 g/mol located on 38 and $44^{\circ} \mathrm{C}$, [39], respectively, while in the DSC curve of the PLA/PEG sample, the crystallization peak is not obvious in the temperature range, but a $T_{\mathrm{g}}$ transition can be noticed. The behavior proved that the PEG is a typical crystalline polymer and the PLA is a semicrystalline polymer with slow rate of crystallization.

Melting process occurs in $153-157^{\circ} \mathrm{C}$ and also shows a small premelting peak at $145^{\circ} \mathrm{C}$. The cold crystallization process can be easily observed only for PLA/PEG/0.5R and PLA/PEG/3CS/0.5R biocomposites in the first heating run between 90 and $92^{\circ} \mathrm{C}$ (Figure 1(a)), while in the second run, this process is present for almost all samples, excepting those with high CS content (Figure 1(b)). Incorporation of a bioactive plasticizer such as PEG led to a decrease of glass transition temperature (from $T_{\mathrm{g}}=66^{\circ} \mathrm{C}$ for PLA to $50-60^{\circ} \mathrm{C}$ for plasticized systems) because of the increase of PLA chain mobility. Other thermal characteristics remain unchanged. All values are similar with those reported in literature [40-42] and in our previous paper for PLA plasticized with ATBC [20].

Some authors found differences in thermal behavior in respect with PLA containing essential oils (EOs). It was found that both PEG and EOs led to the formation of flexible $\mathrm{PLA} / \mathrm{PEG} / \mathrm{EO}$ films with significant drop in the glass transition temperature $\left(T_{\mathrm{g}}\right)$ and mechanical property [43]. The lower enthalpy values for the melt crystallization could be affected by evaporation or degradation of essential oils. A change in thermal properties of PLA indicates the extent of the plasticizing effect provided by EOs, and those decreases could be ascribed to the increase in the chain mobility of polymer matrix. A similar drop in thermal properties has been reported for thymol and cinnamaldehyde-enriched PLA films $[44,45]$. Kamthai and Magaraphan studied the PLA/bagasse carboxymethyl cellulose composites and found that the increment of isosorbide diester plasticizer concentration decreased glass transition, melting, and decomposition temperatures, as well as the reduction of storage modulus, while their elongation was significantly improved with increasing plasticizer content. The results were explained by the synergistic effect of the isosorbide diesters which caused a lowering $\mathrm{Tg}$ (acting as a lubricant) and an increase of the chain mobility at low temperature, but they also induced a cold crystallization acting as nucleating agents. The melting temperature $\mathrm{Tm}$ was reduced. The composite with $15 \mathrm{wt} \%$ isosorbide diesters showed higher $T_{\mathrm{m}}$, so at this concentration, the system showed a better thermal stability than the others $[41,42]$.

The addition of chitosan into plasticized PLA increased the $X_{c}$ up to $\sim 26-29 \%$ especially at low CS amount ( $3 \mathrm{wt} \%)$ when compared with the samples without CS and with PEG-plasticized PLA ( $X_{c}$ of 25\%) (see Table 1 and ref. $29)$. The increase in the crystallinity degree has a decrease effect of impact strength $[16,18]$.

In the present study, the addition of CS to PLA-based systems shifted the $T_{\mathrm{g}}$ to slightly higher values while the cold crystallization to lower temperatures showing that the CS can promote the crystallization of PLA. This is in accordance with results of other authors who also found that chitosan acts as a nucleating agent, promoting a faster crystallization of PLA. A significant improvement in tensile, flexural, and impact strength of the hybrid composites was observed as the weight percentage of Basalt Fiber (BF) and CS increases. Glass transition temperature $\left(T_{\mathrm{g}}\right)$ and percentage of crystallinity $\left(X_{\mathrm{c}}\right)$ increase, as weight percentage of $\mathrm{BF}(25 \%)$ and CS (10\%) increases as showed by DSC measurements [46]. When recording the DSC curves by cooling (not shown), a crystallization temperature was found occurring between 70 and $80^{\circ} \mathrm{C}$, whose values increased with increasing CS content of the biocomposites. This could be due to the restriction in chain reorganization in CS presence, probably because of phase separation. PEG is a typical low molecule polymeric plasticizer. It is recognized as the most studied promoter for PLA, manifesting the desirable compatibility with PLA even at the loading up to $30 \mathrm{wt} \%$. The enhancement of the growth rate of PLA spherulites by the presence of PEG is well documented [47]. Lai et al. [48] found that its action as nucleation agent and promoter may dramatically improve the crystallization kinetics of the polymer matrix.

3.2. Chemiluminescence. The properties of polymer blends/biocomposites reflect usually the contribution of components. When oxidation is the discussed process, the results depend of the mechanistic features of interphase interactions. The thermal stability of PEG-plasticized PLA-based systems is characterized by analogous aspects which gather the present nonisothermal chemiluminescence spectra in two groups (Figure 2). The presence of shoulders was observed at two different temperatures: $150^{\circ} \mathrm{C}$ for the samples containing CS and control (PLA/PEG) and $175^{\circ} \mathrm{C}$ for the samples, where rosemary acts as a stabilizer agent. This shift could have occurred due to the protection activity of active components of natural extract on the decomposition of hydroperoxides.

The progress of degradation is much clear at a moderate heating rate of $5^{\circ} \mathrm{C} / \mathrm{min}$. The unrestricted propagation of oxidation is observed at $225^{\circ} \mathrm{C}$ with a maximum CL emission. The $T_{\text {CLmax }}$ is modified for samples containing rosemary extract because it delayed the oxidation process. This is also proved by a slight increase in the activation energy values of R-containing samples (Table 2) because it stimulates the blocking action of the peroxyl radical oxidation. This delay 


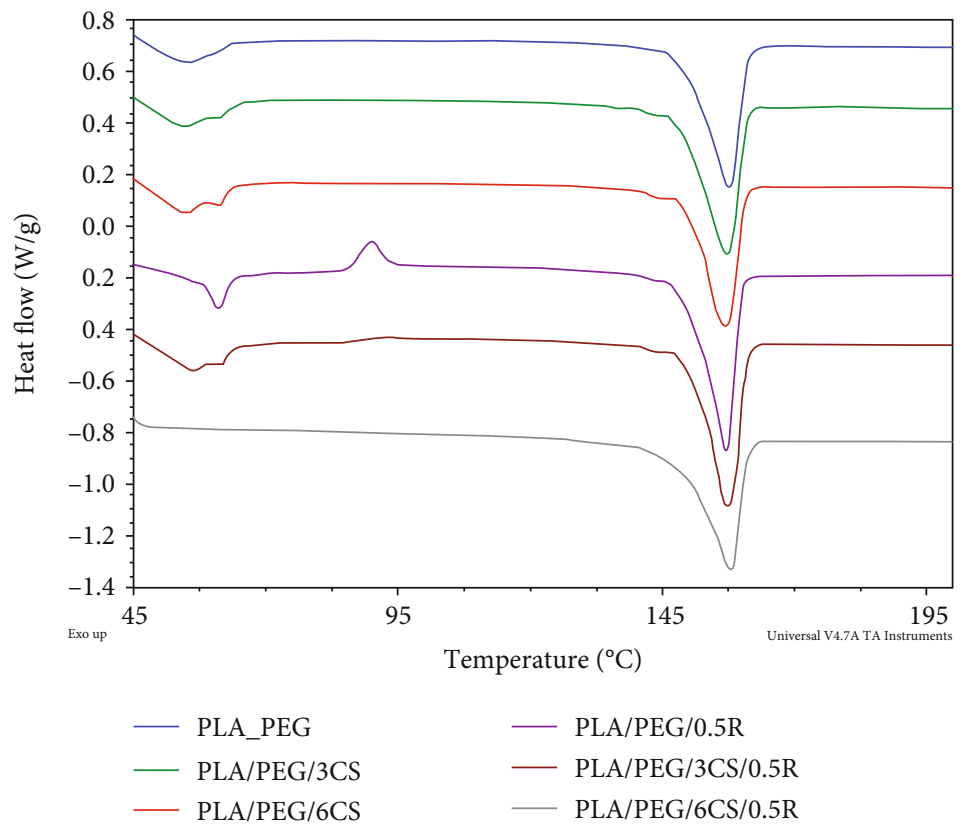

(a)

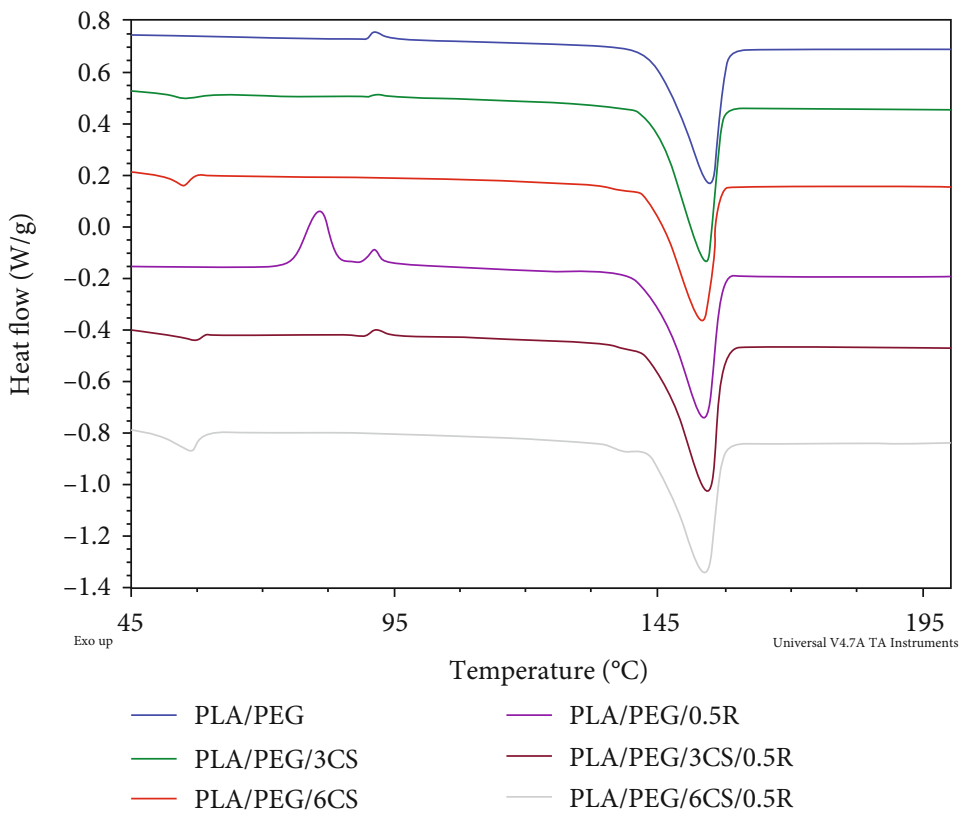

(b)

Figure 1: DSC curves of plasticized PLA, PLA/PEG/R, and PLA/PEG/CS/R biocomposites, recorded in the first heating run (a) and the second heating run (b).

is explained by the scavenging activity of the phenolic components of $\mathrm{R}$ on the free radicals sprung by fragmentation of polymer backbones. While PLA generates radicals by the cleavage of ester units [49], PEG is scissored on the ethylene oxide sites [50]. The contributions of the two components are difficult to be individually evaluated because the oxidation occurs randomly even though rosemary protector is active. However, a prominent CL peak is present in the PLA/PEG blend, which allows supposing that $\mathrm{R}$ has a concealing action on the main biocomposite component.
If the thermal behaviors based on activation energy of the PLA/PEG/CS and PLA/PEG compositions are compared, the improvement in the thermal stability of the former blend can be noticed. The temperature shift toward greater values when chitosan and rosemary are present is a confirmation of their collaboration in the propagation steps of oxidation.

The values of onset oxidation temperature follow some certain tendencies (Table 2 and Figure 3). The CS at low concentration decreases the OOT values especially at small heating rates but a tendency to increase it was found at higher 
TABLE 1: Thermal characteristics of the plasticized PLA/PEG/CS/R systems determined by the DSC method.

\begin{tabular}{|c|c|c|c|c|c|c|c|}
\hline Sample & $T_{\mathrm{g}}\left({ }^{\circ} \mathrm{C}\right)$ & $T_{\mathrm{cc}}\left({ }^{\circ} \mathrm{C}\right)$ & $\Delta H_{\mathrm{cc}}(\mathrm{J} / \mathrm{g})$ & $T_{\mathrm{m}}\left({ }^{\circ} \mathrm{C}\right)$ & $\Delta H_{\mathrm{m}}(\mathrm{J} / \mathrm{g})$ & $T_{\mathrm{cr}}\left({ }^{\circ} \mathrm{C}\right)$ & Crystallinity degree $X(\%)$ \\
\hline \multicolumn{8}{|c|}{ For the first heating run } \\
\hline $\mathrm{PLA} / \mathrm{PEG}$ & $49.3 ; 54.1$ & - & - & 157.7 & 23.8 & 70.0 & 25.1 \\
\hline PLA/PEG/3CS & 49.2 & - & - & 157.4 & 27.9 & 73.1 & 29.8 \\
\hline PLA/PEG/6CS & $50.1 ; 60.8$ & - & - & 157.0 & 24.9 & 77.8 & 26.6 \\
\hline PLA/PEG/0.5R & $53.6 ; 60.2$ & 90.2 & 2.6 & 157.1 & 26.1 & 66.7 & 27.9 \\
\hline PLA/PEG/3CS/0.5R & $50.5 ; 60.8$ & 92.5 & - & 157.3 & 26.4 & 70.7 & 28.2 \\
\hline PLA/PEG/6CS/0.5R & - & - & - & 157.9 & 26.2 & 80.5 & 27.9 \\
\hline \multicolumn{8}{|c|}{ For the second heating run } \\
\hline PLA/PEG & - & 91.4 & 0.36 & 154.7 & 25.3 & - & 27.0 \\
\hline PLA/PEG/3CS & 53.8 & 91.6 & - & 153.8 & 27.8 & - & 29.7 \\
\hline PLA/PEG/6CS & 52.7 & - & - & 153.3 & 25.4 & - & 27.1 \\
\hline PLA/PEG/0.5R & - & 80.9 & 8.00 & 153.7 & 27.3 & - & 29.1 \\
\hline PLA/PEG/3CS/0.5R & 54.6 & 91.6 & 0.34 & 154.3 & 27.6 & - & 29.5 \\
\hline PLA/PEG/6CS/0.5R & 52.3 & - & - & 153.6 & 26.7 & - & 28.5 \\
\hline
\end{tabular}

Glass transition $\left(T_{\mathrm{g}}\right)$, cold crystallization $\left(T_{\mathrm{cc}}\right)$, melting $\left(T_{\mathrm{m}}\right)$, and crystallization $\left(T_{\mathrm{cr}}\right)$ temperatures; cold crystallization $\left(\Delta H_{\mathrm{cc}}\right)$ and melting $\left(\Delta H_{\mathrm{m}}\right)$ enthalpies; crystallinity degree $(X)$.

heating rates. The presence of rosemary has an unexpected decreasing effect. This apparent behavior is conducted by the degradation of PLA, which takes place in two stages: a decomposition process and an oxidation in the bulk. As it is shown in Figure 2, the generation of hydroperoxides is notified by an oxidation peak. Furthermore, the increase in the concentration of CS leads to a disappearance of this CL emission shoulder followed by a significant increase of OOT (Figure 3). The highest OOT values are found for PLA/PEG/6CS and PLA/PEG/6CS/R biocomposites (Figure 3(b)). For each sample, OOT increases with increasing heating rate that may be the consequence of the increase of thermal movement of structural entities, especially small scission moieties.

Two mechanistic details can be analyzed: the small fragments from PLA consume a part of rosemary and the protector role of the last involved in the oxidation inhibition of primary large radicals. The increase of temperature does not make a difference between the various coexisting intermediates. The competition for rosemary in the blocking radicals generated by blending components determines higher values of activation energies. This feature is realistically based on the easier access of small fragments for the stabilization action instead of the inactivation of former radicals with larger chain configuration.

The thermal degradation of biocomposite components, PLA and PEG, occurs by macromolecule decomposition. The fragmentation of PLA and PEG chains is the main process through which these polymers are degraded. The formation of formic esters from PEG [50] and lactides from PLA [49] describes the sharp decrease in their molecular weights. According with previous results on the activation energy values required for the thermal degradation of PLA [51], the present data (Table 2) are placed on the lower limit. Other estimations reported various values that depend on the chosen method $[52,53]$. Indeed, the sample composition plays a key role in the energetic characterization of degradation process.
On the beginning of oxidation, first 10 minutes, occurring in PLA/PEG blends, the evolution of degradation takes at different places if rosemary is present or not (Figure 4).

The dropping of the CL intensities in the samples free of rosemary alcoholic extract explains the lack of any oxidation prevention. The free radicals that appeared during sample preparation are immediately oxidized, and their decay is reflected in the variation of emission intensities. By contrast, the rosemary extract blocks the oxidation of neighboring radicals for a short time on the first minutes. For the two pairs of compositions, the isothermal CL curves drawn in the presence of $\mathrm{R}$ are placed under the similar curves recorded on free rosemary samples. It reveals the involvement of natural phenolic antioxidants in the diminution of oxidative ageing of PLA. The further reactions with oxygen will involve the spread of radicals that are formed during thermal testing at $170^{\circ} \mathrm{C}$. The amplitudes of increasing CL intensities are higher in respect with the intensities recorded at 10 minutes of heating, in the samples without $\mathrm{R}$. The PLA/PEG sample shows the well-defined maximum emission values after 10 minutes. The next parts of CL spectra start suddenly in the stabilized composition. In the formulation free of $\mathrm{R}$, radicals are available for oxidation describing a pseudoplateau followed by a smooth increase. The pairs consisting of specimens, PLA/PEG/3CS and PLA/PEG/3CS/R, exhibit intensity peaks at 40 and 50 minutes, respectively. The curve slope for rosemary-containing sample decreases more gradually than the curve drawn for unprotected blend. For other pairs, PLA/PEG/6CS and PLA/PEG/6CS/R where the higher content of CS is present, the evolution of CL intensities is slower where $\mathrm{R}$ natural protection acts efficiently. These CL results confirm the benefic contribution of $\mathrm{R}$ and the degrading trend induced by CS. The biocomposites with PLA as a main phase (matrix) demonstrate that the progress of oxidative degradation requires activation energies not more than $55 \mathrm{~kJ} \mathrm{~mol}^{-1}$. Because the blends stabilized with $\mathrm{R}$ exhibit slightly higher values of apparent activation energy 


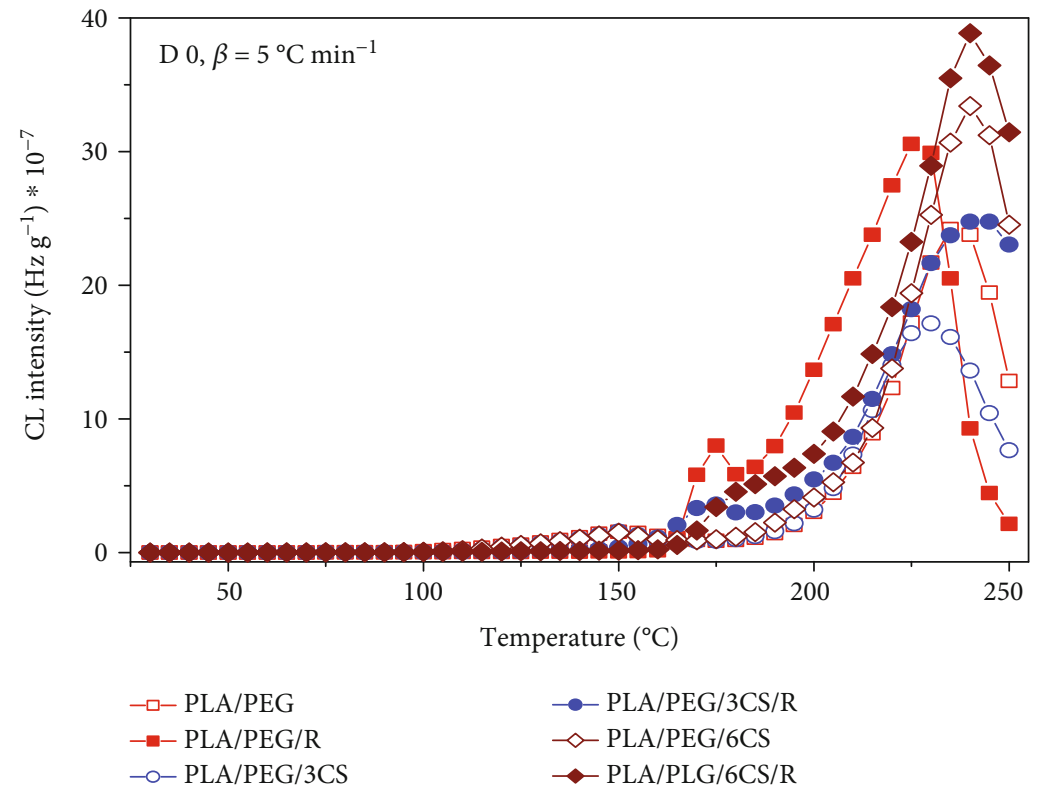

FIgURE 2: The dependence of the CL intensity on temperature for plasticized PLA-based system of various compositions: all samples PLA/PEG and PLA/PEG/CS; PLA/PEG/R and PLA/PEG/CS/R.

TABLE 2: Onset oxidation temperature (OOT) and apparent activation energy (Ea) for the oxidation of the PLA/PEG and PLA/PEG/CS/R biocomposites determined by nonisothermal chemiluminescence method at different heating rates.

\begin{tabular}{|c|c|c|c|c|c|}
\hline Sample & Heating rate $\left({ }^{\circ} \mathrm{C} \mathrm{min}^{-1}\right)$ & OOT $\left({ }^{\circ} \mathrm{C}\right)$ & Equation & Correlation coefficient & $\mathrm{Ea}\left(\mathrm{kJ} \mathrm{mol}^{-1}\right)$ \\
\hline \multirow{4}{*}{ PLA/PEG } & 3.7 & 185 & \multirow{4}{*}{$Y=2.71-6.29 X$} & \multirow{4}{*}{0.98344} & \multirow{4}{*}{52.54} \\
\hline & 5.0 & 201 & & & \\
\hline & 10.0 & 218 & & & \\
\hline & 15.0 & 231 & & & \\
\hline \multirow{4}{*}{ PLA/PEG/3CS } & 3.7 & 179 & \multirow{4}{*}{$Y=2.55-6.14 X$} & \multirow{4}{*}{0.97148} & \multirow{4}{*}{51.05} \\
\hline & 5.0 & 197 & & & \\
\hline & 10.0 & 212 & & & \\
\hline & 15.0 & 225 & & & \\
\hline \multirow{4}{*}{ PLA/PEG/6CS } & 3.7 & 192 & \multirow{4}{*}{$Y=2.71-6.29 X$} & \multirow{4}{*}{0.98344} & \multirow{4}{*}{52.30} \\
\hline & 5.0 & 208 & & & \\
\hline & 10.0 & 220 & & & \\
\hline & 15.0 & 232 & & & \\
\hline \multirow{4}{*}{ PLA/PEG/R } & 3.7 & 182 & \multirow{4}{*}{$Y=3.15-6.38 X$} & \multirow{4}{*}{0.99378} & \multirow{4}{*}{53.04} \\
\hline & 5.0 & 188 & & & \\
\hline & 10.0 & 208 & & & \\
\hline & 15.0 & 225 & & & \\
\hline \multirow{4}{*}{ PLA/PEG/3CS/R } & 3.7 & 180 & \multirow{4}{*}{$Y=2.95-6.33 X$} & \multirow{4}{*}{0.97528} & \multirow{4}{*}{52.63} \\
\hline & 5.0 & 196 & & & \\
\hline & 10.0 & 215 & & & \\
\hline & 15.0 & 223 & & & \\
\hline \multirow{4}{*}{ PLA/PEG/6CS/R } & 3.7 & 192 & \multirow{4}{*}{$Y=3.40-6.65 X$} & \multirow{4}{*}{0.89551} & \multirow{4}{*}{55.29} \\
\hline & 5.0 & 216 & & & \\
\hline & 10.0 & 224 & & & \\
\hline & 15.0 & 245 & & & \\
\hline
\end{tabular}




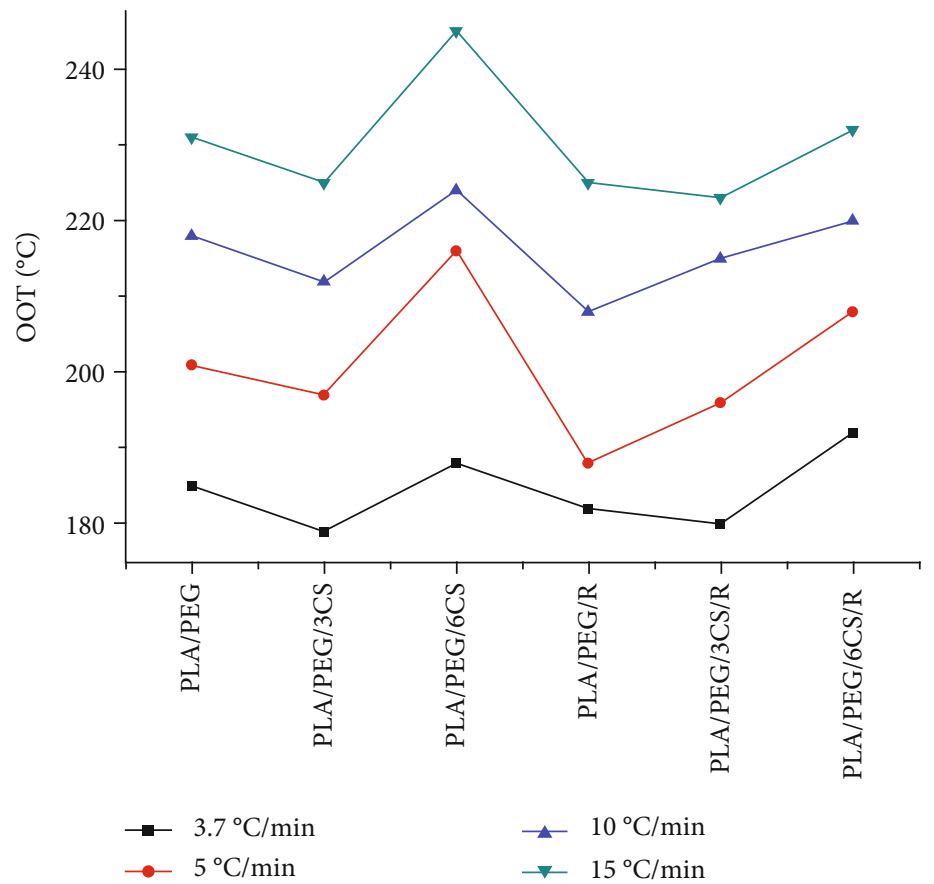

(a)

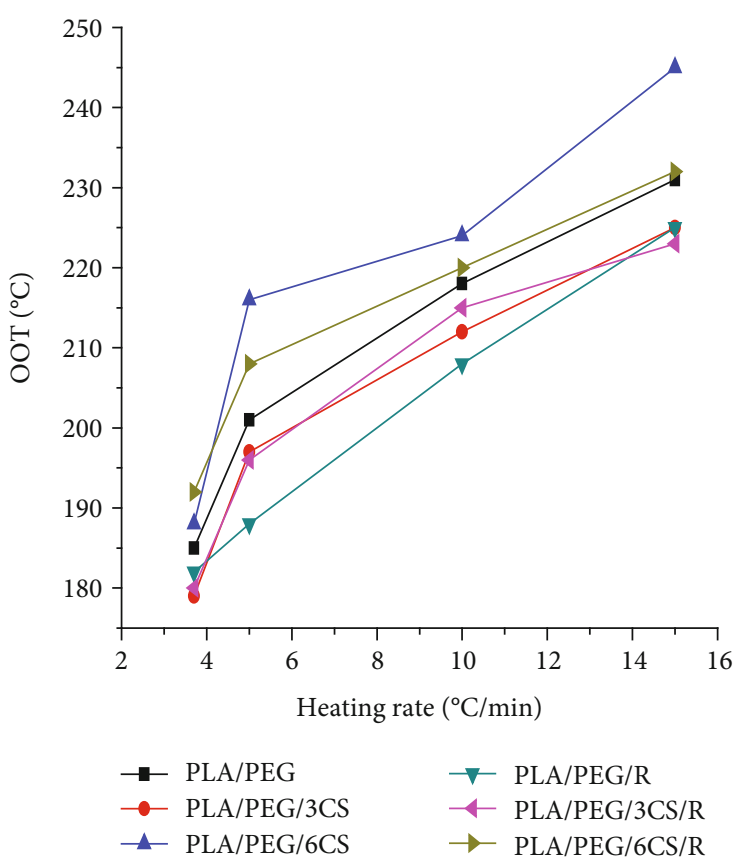

(b)

Figure 3: Dependence of OOT on sample composition (a) and on heating rates (b).

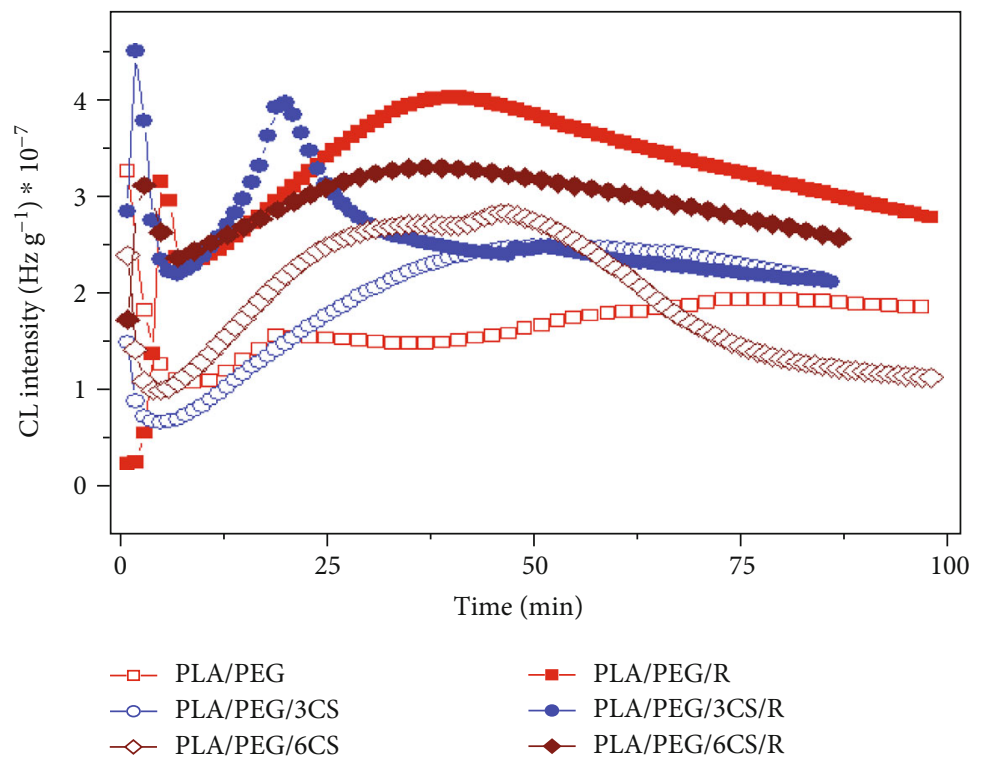

Figure 4: CL spectra for plasticized PLA samples of various compositions recorded in isothermal conditions at $170^{\circ} \mathrm{C}$.

that there were found for samples free of oxidation protector, the presence of rosemary extract is a reliable solution for the improvement of thermal stability of PLA. It means that only a small part of molecules is converted into peroxyl radicals and the most part of materials is decomposed onto lowweight fragments.

From the data of Table 3, two main features can be envisaged: (1) the activation energies (Ea) required by unstabilized samples are similar with the values found for poly (lactic acid)
[51], and (2) because the differences in the activation energies involved in the oxidative degradation of homologous compositions are small, the presence of phenolic components from rosemary extract hinders only the oxidation of scission fragments, the depolymerization being unaffected. Furthermore, the lower contents of chitosan drops smoothly down the value of activation energy due to its concerns in the propagation of oxidation. The oxidative degradation of polymers starts with the scission of weaker bonds and the formation 
TABLe 3: TG data for PEG-plasticized PLA containing chitosan and powdered rosemary ethanolic extract.

\begin{tabular}{|c|c|c|c|c|c|c|c|c|}
\hline Sample & Degradation step & $T_{\text {onset }}\left({ }^{\circ} \mathrm{C}\right)$ & $T_{\max }\left({ }^{\circ} \mathrm{C}\right)$ & $\Delta W(\%)$ & $T_{10}\left({ }^{\circ} \mathrm{C}\right)$ & $T_{20}\left({ }^{\circ} \mathrm{C}\right)$ & \multicolumn{2}{|c|}{ GS $\left({ }^{\circ} \mathrm{C}\right)$} \\
\hline \multirow{3}{*}{ PLA/PEG } & I & 276.8 & 321.4 & 82.52 & 285.5 & 298 & 334 & (337) \\
\hline & II & 372.2 & 401.5 & 16.30 & & & \multirow{2}{*}{394} & \multirow{2}{*}{$(400)$} \\
\hline & Residue & & & 1.18 & & & & \\
\hline \multirow{3}{*}{ PLA/PEG/3CS } & I & 280.8 & 325.8 & 73.72 & 290.2 & 294 & 325 & (334) \\
\hline & II & 369.2 & 409.4 & 20.40 & & & \multirow{2}{*}{\multicolumn{2}{|c|}{$(407)$}} \\
\hline & Residue & & & 5.88 & & & & \\
\hline \multirow{3}{*}{ PLA/PEG/6CS } & I & 285.8 & 323.3 & 79.38 & 292.5 & 304.5 & 336 & $(332)$ \\
\hline & II & 371.1 & 402 & 18.48 & & & \multirow{2}{*}{394} & \multirow{2}{*}{$(410)$} \\
\hline & Residue & & & 2.14 & & & & \\
\hline \multirow{3}{*}{ PLA/PEG/0.5R } & I & 284.8 & 336.4 & 83.03 & 294 & 307.5 & 348 & $(342)$ \\
\hline & II & 375.3 & 402.8 & 15.04 & & & \multirow{2}{*}{\multicolumn{2}{|c|}{$(415)$}} \\
\hline & Residue & & & 1.93 & & & & \\
\hline \multirow{3}{*}{ PLA/PEG/3CS/0.5R } & I & 282.7 & 329.7 & 69.15 & 293.5 & 312.6 & 345 & (343) \\
\hline & II & 370.3 & 395.4 & 21.36 & & & \multirow{2}{*}{\multicolumn{2}{|c|}{ (399) }} \\
\hline & Residue & & & 9.49 & & & & \\
\hline \multirow{3}{*}{ PLA/PEG/6CS/0.5R } & I & 294.7 & 332.6 & 79.77 & 303 & 314 & 341 & (340) \\
\hline & II & 377.5 & 406.1 & 17.96 & & & \multirow{2}{*}{406} & \multirow{2}{*}{$(410)$} \\
\hline & Residue & & & 2.27 & & & & \\
\hline
\end{tabular}

Decomposition temperatures: $T_{\text {onset }}$ : onset of decomposition; $T_{\max }$ : temperature corresponding to maximum mass loss rate and corresponding to $10 \%\left(T_{10}\right)$ and $20 \%\left(T_{20}\right)$ mass loss $(\Delta W)$; GS: the temperature at which the maximum amount of gas was released (determined from Gram-Schmidt curves using Proteus software while in brackets are values evaluated from 3D spectra using OPUS programme) from each decomposition step. The accordance of both types of GS values is evident.

of intermediates as the initiators of propagation stages [54]. The formation and the decay of peroxyl radicals are proved by the emission peak appeared in the nonisothermal CL spectra at $150^{\circ} \mathrm{C}$ and $175^{\circ} \mathrm{C}$ for the oxidative degradation of samples free of R (Figure 4) and rosemary-protected polymer blends (Figure 4), respectively. This difference is an evident proof of antioxidant activity of rosemary extract by the increasing formation temperature with $25^{\circ} \mathrm{C}$, a significant value in the kinetic analysis of the stability of studied systems.

The further reactions involving free radicals (see Scheme 1) follow various routes when the interaction between the entities born from both polymers voids the generation of oxidation products.

The evolution of oxidation depicted by Figure 4 is an additional proof for the stability protection brought about by R. The best example is the pair curves recorded for PLA/PEG/6CS in the presence and free of rosemary extract. The maximum CL intensities are reached after 29 minutes, when the sample is protected, while the unstabilized sample has the corresponding peak after 20 minutes at the same temperature $\left(170^{\circ} \mathrm{C}\right)$. Analogous evidences may take into consideration the main role of $\mathrm{R}$ in the delay of oxidative degradation of studied blends. The former entities that appeared by molecular chain scissions were presented earlier $[55,56]$. They follow different paths by which they are decayed: either the formation of peroxyl intermediates generates stable oxidation products or they interact to each other coupling them in larger structures. The present CL measurements on PLA/PLG blends with and without rosemary suggest the general scheme depicting the degradation of PLA/PEG formulations. Microstructural differences were also described by other authors studying PLA-b-PEG-b-PLA triblock copolymer [57]. The addition of oxidation protector directs the radicals appearing from both components toward their interaction by intermolecular configurations [58]. The abundances of oxygenated products born by various propagation reactions, like molecular rearrangements or transesterification, are diminished by the presence of $\mathrm{R}$, which provides increasing amounts of lactide and carbonyl derivatives. The most important role of methyl moieties in PLA degradation consists of the involvement of small radicals in the decay of macroradicals $[55,59]$. The ESR investigations have stated that the tertiary methyls are easily radiolised explaining the decrease of molecular weight of components.

3.3. TG/DTG/FTIR/MS Study. Thermal stability, including initial decomposition temperature $\left(T_{\text {onset }}\right)$, temperature of maximum rate of degradation $\left(T_{\max }\right)$, decomposition temperature at $10 \%$ and $20 \%$ weight loss $\left(T_{10}\right.$ and $\left.T_{20}\right)$, and, respectively, GS temperature-the temperature at which the maximum amount of gas was released (determined from Gram-Schmidt curves using Proteus software) of the PEGplasticized PLA materials, can be determined by thermogravimetry. The TG/DTG curves of the biocomposites are given in Figures 5(a) and 5(b), while the thermogravimetric data are summarized in Table 3 . According to the previous results [25] and literature data [60-65], thermal degradation of PLA is a single-step process involving the nonradical decomposition, radical alkyl-oxygen homolysis, and radical acryloxygen homolysis. This polymer material is the precursor to the formation of an intramolecular transesterification, which undergoes ester pyrolysis and unzipping depolymerization 


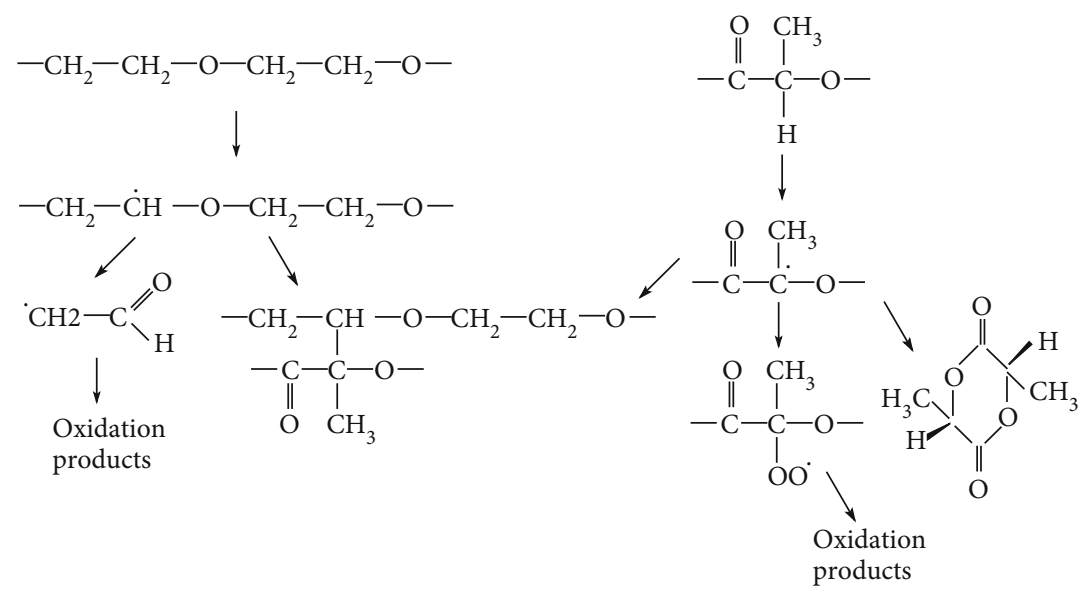

Scheme 1: Oxidative mechanism scheme of PLA/PEG blends.

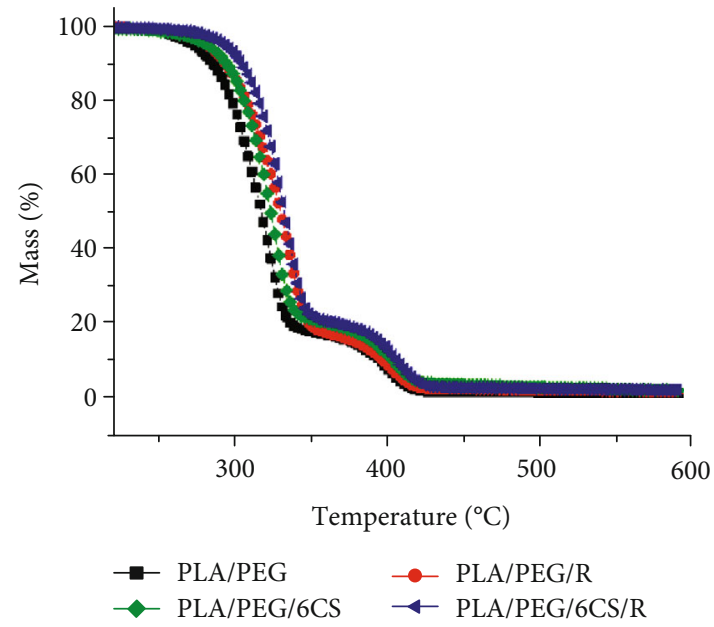

(a)

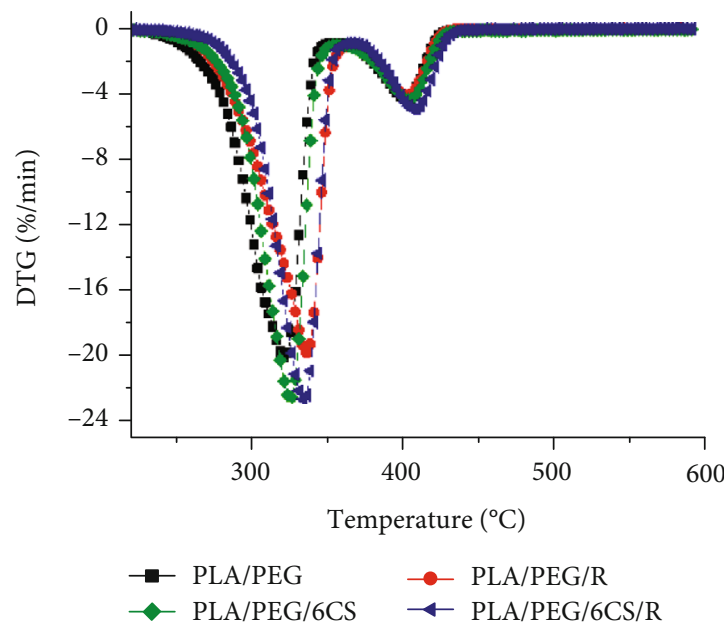

(b)

FIGURE 5: TG (a) and DTG (b) curves for PLA-based blends and biocomposites containing PEG, chitosan, and rosemary ethanolic extract.

random chain scission. The PEG-plasticized PLA decomposes in two steps occurring between $270-375^{\circ} \mathrm{C}$ and $375-$ $430^{\circ} \mathrm{C}$ temperature ranges. The decomposition of all other biocomposites is similar with that of plasticized PLA with some particularities offered by each active component chitosan or/and rosemary ethanolic extract. The first step which is the main one occurs with a mass loss $(\Delta W)$ of $69-83 \mathrm{wt} \%$, while the second that takes place shows a mass loss of 15$21 \mathrm{wt} \%$. The residue amount is higher after decomposition of the biocomposites containing chitosan, because of the carbonization process occurring in polysaccharides. It can easily be observed from Figures 5(a) and 5(b) that by incorporating both of the CS and rosemary extract, the curves are shifted to higher temperatures proving that the new multicomponent materials are more thermostable than plasticized PLA.

The highest onset $\left(T_{\text {onset }}\right)$ temperature of decomposition start, maximum $\left(T_{\max }\right)$ decomposition temperature corresponding to maximum rate of mass loss, GS and decomposition temperature corresponding to $10 \mathrm{wt} \%\left(T_{10}\right)$ and $20 \mathrm{wt} \%$ $\left(T_{20}\right)$ mass loss, respectively, are found for the PLA/PEG/6CS and PLA/PEG/CS/R biocomposites (Table 3). This variation appears much clearer in Figure 6. This means that in these biocomposites, both bioactive components act synergistically for improving thermal stability of materials. Similar results were found in other papers as for PLA/epoxidized vegetable oils [66]. Other authors found that at temperatures $<250^{\circ} \mathrm{C}$, the nanocomposites exhibited good thermal stability and could effectively block about $65 \%$ of UVB and UVC irradiation [67]. For other types of materials, the thermal behavior is different. Isosorbide diesters decreased the $T_{\max }$ of plasticized PLA/carboxymethyl cellulose (CMCB) composites with the narrow range, i.e., by $10^{\circ} \mathrm{C}$. The composite with $20 \mathrm{wt} \%$ of plasticizer showed a two-step decomposition; the major decomposition of PLA/CMCB occurs in the temperature range of $250-350^{\circ} \mathrm{C}$ [41]. In the $\mathrm{PLA} / 5 \%$ microcrystalline cellulose (MCC) binary composites, a shift to lower temperatures of about $10^{\circ} \mathrm{C}$ in $T_{\max }$ value was observed, while a decrease of about $25^{\circ} \mathrm{C}$ was detected for the PLA/5MCC/1Ag ternary composite which indicates that combining the presence of microcrystalline cellulose and silver nanoparticles affects the thermal degradation process. As degradation proceeds, the effect of the hydrogen bonding interactions 


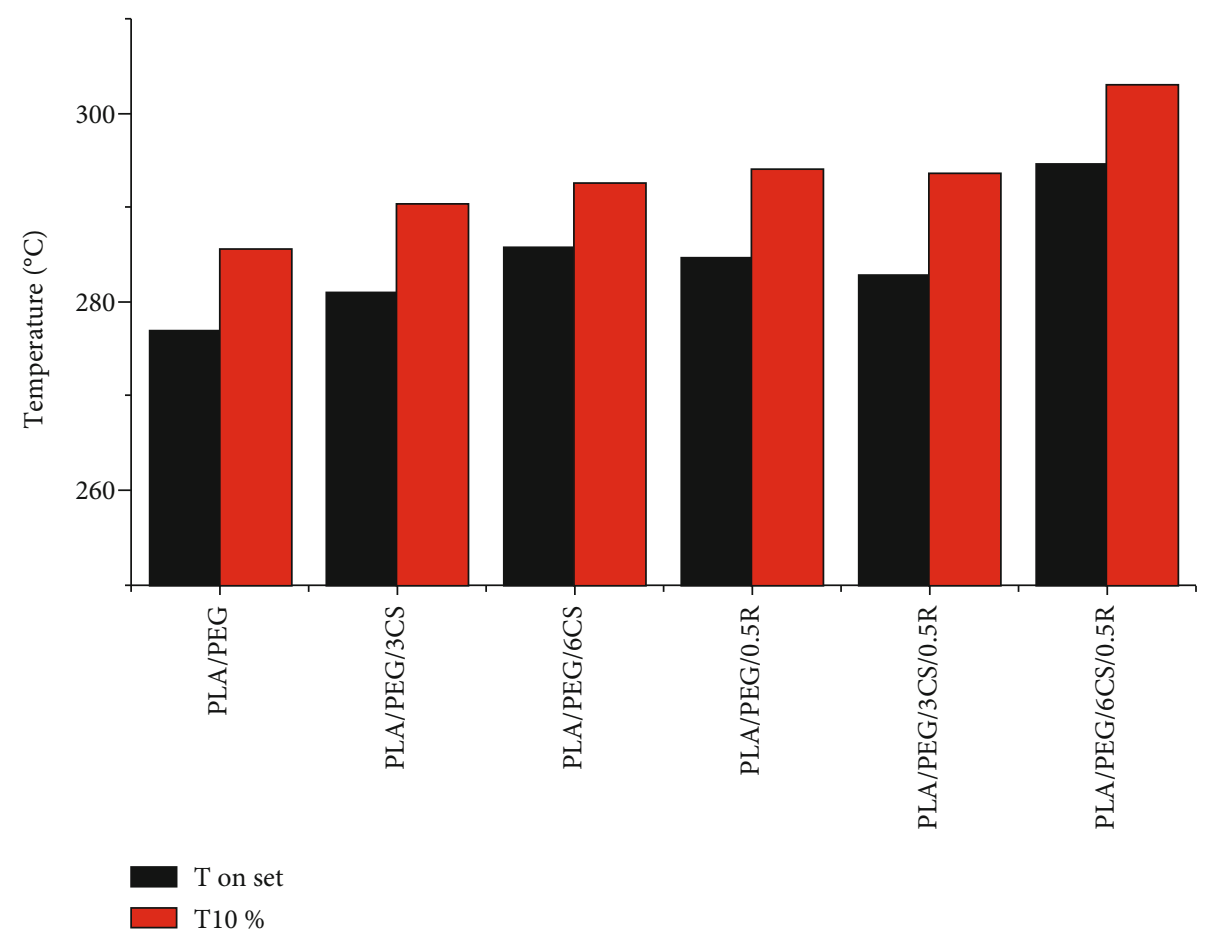

FIgURE 6: The variation of the $T_{\text {onset }}$ and $T_{10}$ with the composition of PEG-plasticized PLA biocomposite.

decreases, but char and gases evolved from cellulose degradation may interact with solid PLA [68].

The processing of thermogravimetric data obtained after thermal degradation was performed using the "Thermokinetics-3" software (Netzsch “Thermokinetics-3," version 2008.05). By using 18 different reaction models included in the software, the multiple linear regression (MLR) method allows the obtaining of the most probable kinetic model, describing each thermal degradation step through a comparison between recorded nonisothermal experimental data and calculated data.

The conversion equations $f(\alpha)$ that used one single-step model are shown below:

Reaction order $n$th model, sFn:

$$
f(\alpha)=(1-\alpha)^{n}
$$

where $n$ is the reaction order and $\alpha$ is conversion degree.

$n$th reaction order of the autocatalytic model, $\mathrm{CnB}$ :

$$
f(\alpha)=(1-\alpha)^{n}\left(1+K_{\mathrm{cat}} \cdot \alpha\right) .
$$

$K_{\text {cat }}$ is the autocatalytic constant, $n$ is the reaction order, and $\alpha$ is conversion degree.

As it can be seen from the data of Table 4, the sCnB model is characteristic for both the degradation steps of most samples excepting the first one of PLA/PEG/0.5R and PLA/PEG/3CS, while the sFn model describes thermal degradation of PLA/PEG/0.5R both steps, the second step of the PLA/PEG degradation and the first one of PLA/PEG/3CS and PLA/PEG/3CS/0.5R samples. The $n$th model, sFn, is commonly used to check the mechanism of polymer decomposition [69]. It was demonstrated that the autocatalytic degradation mechanism may lead to acceleration of degradation. The autocatalysis manifests in nonmonotonicity of the conversion function, and it has a complex role in the PLGA erosion that leads to size-dependent heterogeneities for uniformly bulk-eroding polymer microspheres [70, 71]. However, in the present study, the autocatalytic constant $\left(K_{\text {cat }}\right)$ took small values. The variation of the apparent activation energy for both decomposition steps (and also corresponding preexponential factor) of thermal degradation on the composition of the PEG-plasticized PLA-based materials is similar with that of characteristic temperatures (Figure 7). The highest $E$ values were found for PLA/PEG/6CS/0.5R biocomposite which should be the most thermally stable one.

The values reported in literature for kinetic parameters of decomposition of systems containing PLA differ in respect with experimental conditions used and evaluation method applied. Yang and Lin [7] found the decomposition reaction of PLA to be of first order with an apparent activation energy of 94.0 and $105.3 \mathrm{~kJ} \mathrm{~mole}^{-1}$ and pre-exponential factor 6.43 $\times 10^{5} \mathrm{~s}^{-1}$ and $1.91 \times 10^{6} \mathrm{~s}^{-1}$, respectively. McNeil and Leiper reported that the pyrolysis was a first-order reaction kinetic equation, the apparent activation energy as $119 \mathrm{~kJ} \mathrm{~mole}^{-1}$ $[71,72]$. Aoyagi et al. also reported a complex change in the activation energy value of $80-160 \mathrm{~kJ} \mathrm{~mole}^{-1}$ [73]. Sivalingam and Madras investigated the thermal degradation of PLA both under conditions of dynamic and isothermal heating. They reported that the apparent activation energies of pyrolysis were 42.7 and $105.4 \mathrm{~kJ} \mathrm{~mole}^{-1}$ for the random chain scission and the specific chain scission for the dynamic heating by using the Friedman analytical method and $92.9 \mathrm{~kJ}$ mole 1 for isothermal conditions of heating, respectively [74]. These values are enough similar with ours taking into consideration the differences between experimental conditions. 
TABLE 4: Kinetic parameters obtained by the multiple linear regression (MLR) method.

\begin{tabular}{|c|c|c|c|c|c|c|c|}
\hline Sample & Temperature range $\left({ }^{\circ} \mathrm{C}\right)$ & Reaction type & $\mathrm{Ea}\left(\mathrm{kJ} \mathrm{mol}^{-1}\right)$ & $\log A\left(\mathrm{~s}^{-1}\right)$ & Reaction order & $\log K_{\text {cat }}$ & Correl coeff. \\
\hline \multirow{2}{*}{ PLA/PEG } & $250-350$ & $\mathrm{sCnB}$ & 143 & 10.44 & 0.93 & -0.110 & 0.9999 \\
\hline & $350-450$ & sFn & 130 & 7.82 & 0.39 & - & 0.9977 \\
\hline \multirow{2}{*}{ PLA/PEG/3CS } & $250-340$ & $\mathrm{sFn}$ & 138 & 11.59 & 2.58 & - & 0.9984 \\
\hline & $340-480$ & $s \mathrm{CnB}$ & 134 & 8.43 & 2.30 & 0.176 & 0.9947 \\
\hline \multirow{2}{*}{ PLA/PEG/6CS } & $250-350$ & $\mathrm{sCnB}$ & 143 & 10.29 & 0.93 & 0.284 & 0.9999 \\
\hline & $340-480$ & $s \mathrm{CnB}$ & 138 & 8.49 & 0.80 & -0.542 & 0.9978 \\
\hline \multirow{2}{*}{ PLA/PEG/0.5R } & $250-350$ & $\mathrm{sFn}$ & 132 & 9.25 & 0.53 & - & 0.9999 \\
\hline & $350-450$ & $\mathrm{sFn}$ & 132 & 7.97 & 0.42 & - & 0.9990 \\
\hline \multirow{2}{*}{ PLA/PEG/3CS/0.5R } & $220-350$ & $\mathrm{sFn}$ & 145 & 12.04 & 1.28 & & 0.9986 \\
\hline & $350-470$ & $\mathrm{sCnB}$ & 152 & 9.29 & 1.90 & 1.147 & 0.9985 \\
\hline \multirow{2}{*}{ PLA/PEG/6CS/0.5R } & $250-350$ & $\mathrm{sCnB}$ & 178 & 13.34 & 0.79 & -0.244 & 0.9999 \\
\hline & $350-480$ & $\mathrm{sCnB}$ & 159 & 9.89 & 0.81 & 0.045 & 0.9992 \\
\hline
\end{tabular}

" $\mathrm{s}$ " indicates that the thermal degradation takes place in one step, and Fn and $\mathrm{CnB}$ represent the single reaction model involved in the thermal degradation process. Ea: apparent activation energy; $A$ : preexponential factor.

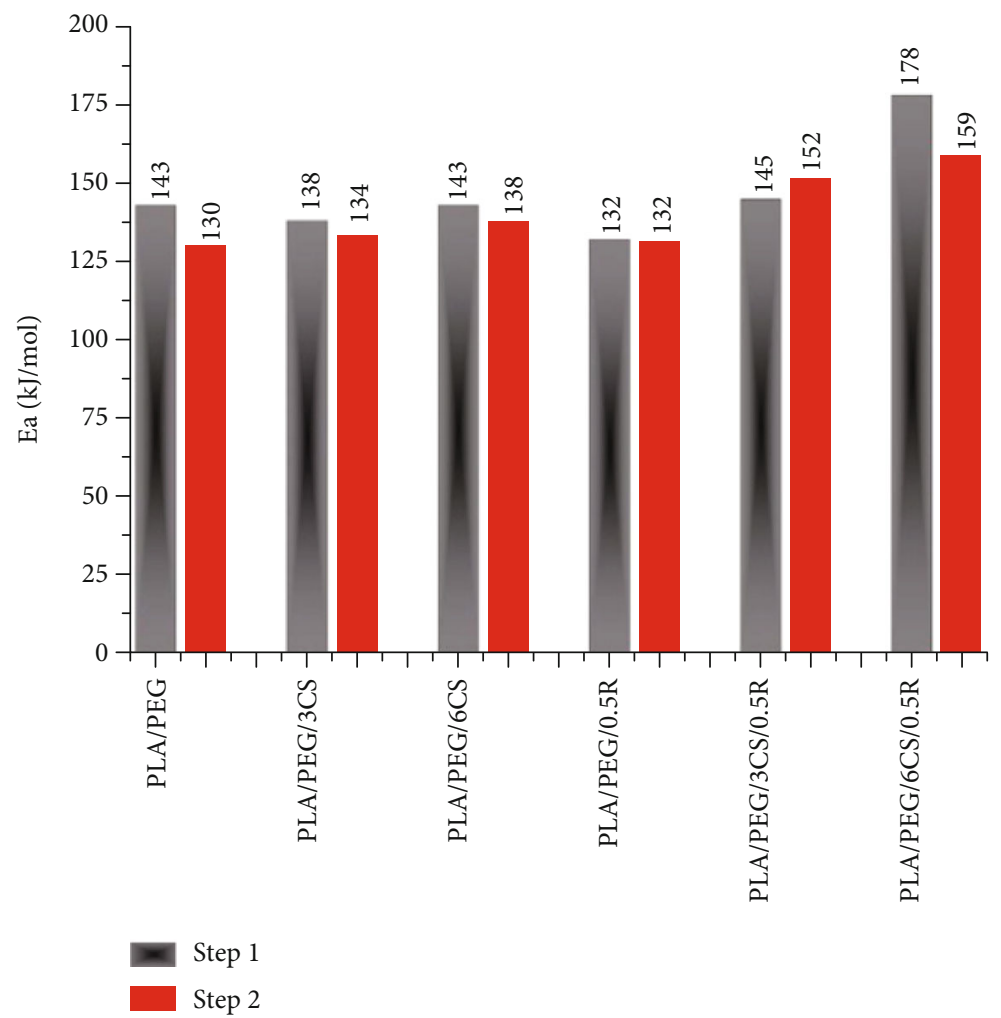

FIGURE 7: Dependence on composition of the apparent activation energy of the first and second step of the thermal decomposition of PEGplasticized PLA-based samples.

Nonisothermal degradation kinetics, proposed by Kissinger, Kissinger-Akahira-Sunose, Flynn-Wall-Ozawa, and Augis and Bennett models, are utilized to estimate the activation energies (Ea) for PLA, which were found to be 254.1, $260.2,257.0$, and $259.1 \mathrm{~kJ} \mathrm{~mol}^{-1}$, respectively. The reduced Ea values of bionanocomposite films may be elucidated by intermolecular distance and enrichment in chain mobility. The evolved gaseous products like hydrocarbons, carbon dioxide, carbon monoxide, and cyclic oligomers are successfully identified with TG-FTIR analysis [75].
3D FTIR spectra of the decomposition products give some information about the change in their composition after incorporation of CS and R. From the data presented in Figure 8, it is evident that the FTIR spectra show difference both in the intensity of the bands and also in the number of bands. The spectra of the products from decomposition of the biocomposites containing CS are much complex in $2000-3000 \mathrm{~cm}^{-1}$, and the main bands appear at higher temperatures.

The 2D FTIR spectra of the degradation products of the plasticized PLA-based biocomposites taken at both GS 


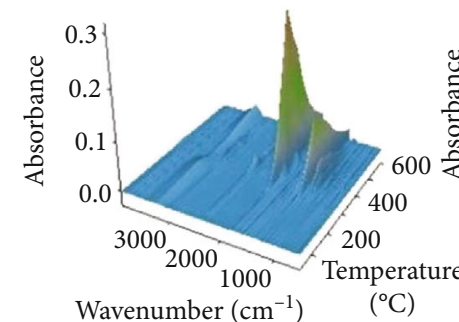

a) PLA/PEG

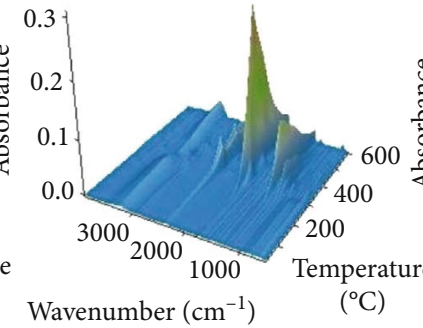

b) PLA/PEG/6CS

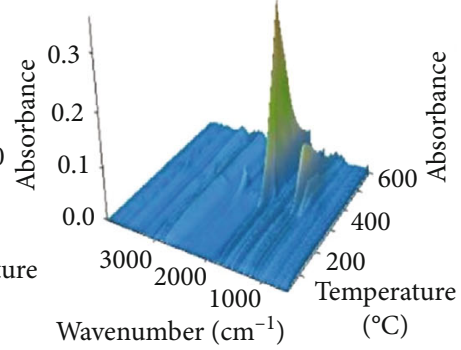

c) PLA/PEG/R

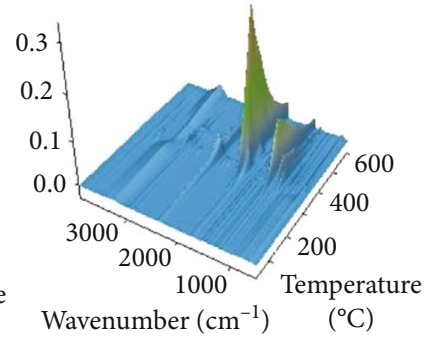

d) PLA/PEG/6CS/R

FIGURE 8: 3D FTIR spectra of the decomposition products of PEG-plasticized PLA biocomposites.

temperatures (Figures 9(a) and 9(b) are almost similar, probably because of the resulting many products that have similar structures and they have overlapped bands which make the interpretation of the spectra difficult. The differences between systems of different compositions are found in $2100-3200 \mathrm{~cm}^{-1}$ and $1300-1700 \mathrm{~cm}^{-1}$ wavenumber regions. At an average maximum gas evolution temperature of 330$340^{\circ} \mathrm{C}$, the following differences are observed (Figure 9(a)): $3253 \mathrm{~cm}^{-1}$ (O-H stretch, H-bonded) and $2820 \mathrm{~cm}^{-1}$ (C-H stretch) are absent in the spectra of PLA/PEG and PLA/$\mathrm{PEG} / 6 \mathrm{CS} / \mathrm{R}$, and the ratios of the intensity of the bands 2360,2321 , and $2362 \mathrm{~cm}^{-1}$ (C=O, C-N, and COO-stretching) are different being clearly spited only in PLA/PEG spectrum. 1681 (carbonyl $\mathrm{C}=\mathrm{O}$ stretch), $1641 \quad(\mathrm{C}=\mathrm{C}$ stretch), 1606, 1550 , and $1489 \mathrm{~cm}^{-1}$ (aromatic domain and $\mathrm{N}-\mathrm{H}$ bending, $\mathrm{C}-\mathrm{O}$ stretching vibration (amide) and $\mathrm{C}-\mathrm{C}$ stretching from phenyl groups, $\mathrm{COO}$ - stretching, and $\mathrm{CH}_{2}$ bending) are present only in the PLA/PEG/R spectrum [76]. These bands probably correspond to the fragments that resulted from $\alpha$ pinene and 1,8-cineole products which may evolve from rosemary ethanolic extract. At an average maximum GS of $400-415^{\circ} \mathrm{C}$ (Figure $9(\mathrm{~b})$ ) besides the abovementioned differences in the spectra corresponding to $330-340^{\circ} \mathrm{C}$ decomposition temperature, the bands in the $2990-2819 \mathrm{~cm}^{-1}$ (C-H stretch and $=\mathrm{C}-\mathrm{H}$ stretch) region are found with different intensity ratios and differences in the $650-930 \mathrm{~cm}^{-1}$ region (=C-H bending, aromatic $\mathrm{sp}^{2} \mathrm{C}-\mathrm{H}$, and alkene $\mathrm{sp}^{2} \mathrm{C}-\mathrm{H}$ bending) again much evident in the PLA/PEG/R spectrum [77]. Much information about the decomposition products are obtained from the MS spectra (Figures 10(a) and 10(b).

Comparing FTIR spectrum results with those obtained from MS of Figure 10 indicates different products that resulted both at the two temperatures at which they are collected and also between different systems. The MS spectra of the decomposition products collected at high temperature show many fragments (Figure 10(b)) in comparison with those from lower decomposition temperature (Figure 10(a)) and also fragments with higher $\mathrm{m} / \mathrm{z}$. Comparing the MS spectra of PLA/PEG with those of PLA/PEG/6CS biocomposite, it is evident that the fragments with low $\mathrm{m} / z$ are fewer in the second spectra at both GS temperatures, because by PLA and chitosan, decomposition results larger fragments. The PLA/PEG/6CS/R biocomposite shows the much complex MS spectra. In all spectra, decomposition products can be identified that resulted from PLA as a large amount of cyclic oligomers through the random degradation process, acetal- dehyde $(\mathrm{m} / \mathrm{z} 15,26$, and 43), 2,3-pentadione, acrylic acid, lactide mesoform, or DL form [78, 79]. Common decomposition products were also $\mathrm{H}_{2} \mathrm{O}, \mathrm{CO}_{2}$, and hydrocarbons ( $m / z$ of $18,44,12-17$, etc., respectively) [80].

Thermal degradation of the chitosan is a complex reaction involving two or even three degradation stages. Hong et al. [81] studied the thermal degradation of chitosan in nitrogen, and they found that it depends on heating rate; the kinetic parameter constants of the thermal degradation vary with the degree of decomposition and increase with the reaction temperature. The degradation process of CS usually begins with random splitting of $\beta$-1,4-glycosidic bonds (depolymerization) followed by $\mathrm{N}$-acetyl linkage (deacetylation). Simultaneously with chitosan chain scission, cleavage and/or destruction of its functional groups (amino, carbonyl, amide, and hydroxyl) occur. In addition, chitosan depolymerization may lead to formation of free radicals which induce oxidation processes. The degradation products identified by GC-MS and that could arise from CS were 5hydroxy-1,3-pentadiene, cyclohex-1-en-6-ol, 4,5-dihydroxypent-1-ene, 1-ethylbenzene, 6-hydroxy-2, 4-hexadinol, and 3,5,6-trihydroxyhexanol [82-84]. The 80 and 67 fragments originate from the d-glucosamine moiety of the polymer and the 60 and 42 fragments from the $\mathrm{N}$-ethyl-d-glucosamine moiety [85].

Several phenolic and terpenic compounds in Rosmarinus officinalis L. were identified by GC-MS as simple phenolics, phenolic acids (caffeic and rosmarinic acid), phenolic diterpenes (carnosic acid), and pentacyclic triterpenes (ursolic, oleanolic, and betulinic acid and betulin) and flavonoids $[26,86,87]$. These compounds are different from those arising from the other two components of the studied systems explaining the differences between FTIR and MS spectra recorded for decomposition products at various temperatures and different compositions.

An efficient heating method is necessary to get maximum benefits of antioxidant compounds. Degradation of carnosic acid, carnosol, rosmarinic acid, and a mixture of three was studied by Zhang and others [88] by using HPLC. Several degradation products also formed by exposure to light. Ethanolic standards for rosemary extract were tested in various conditions, for example, carnosic acid, carnosol, rosmarinic acid, and a mixture of three exposed to six different conditions such as $-10^{\circ} \mathrm{C}, 4^{\circ} \mathrm{C}$ in the dark, room temperature with light exposure, room temperature in the dark, $40^{\circ} \mathrm{C}$ with light exposure, and $40^{\circ} \mathrm{C}$ in the dark. The effect of temperature and 


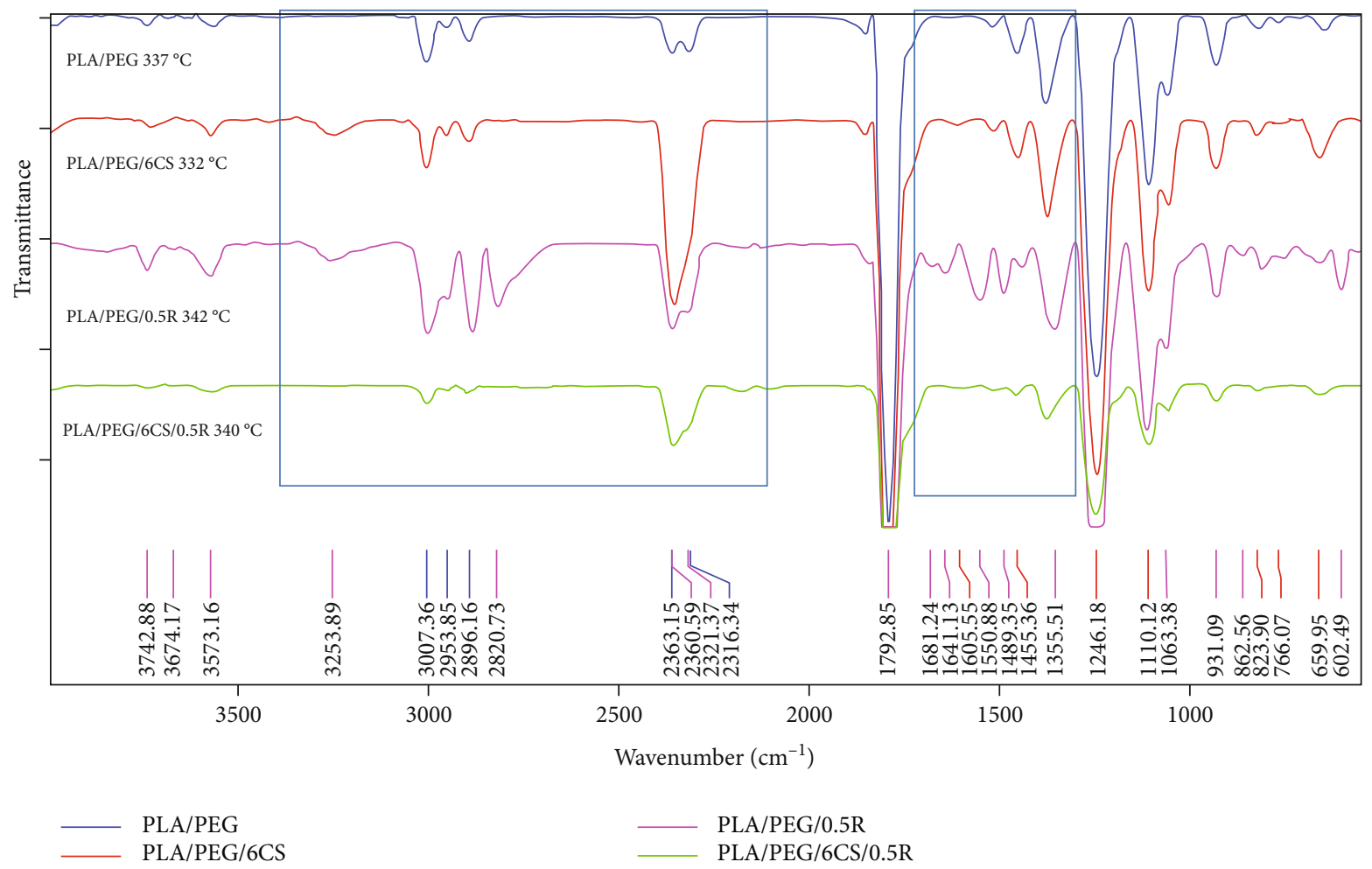

(a)

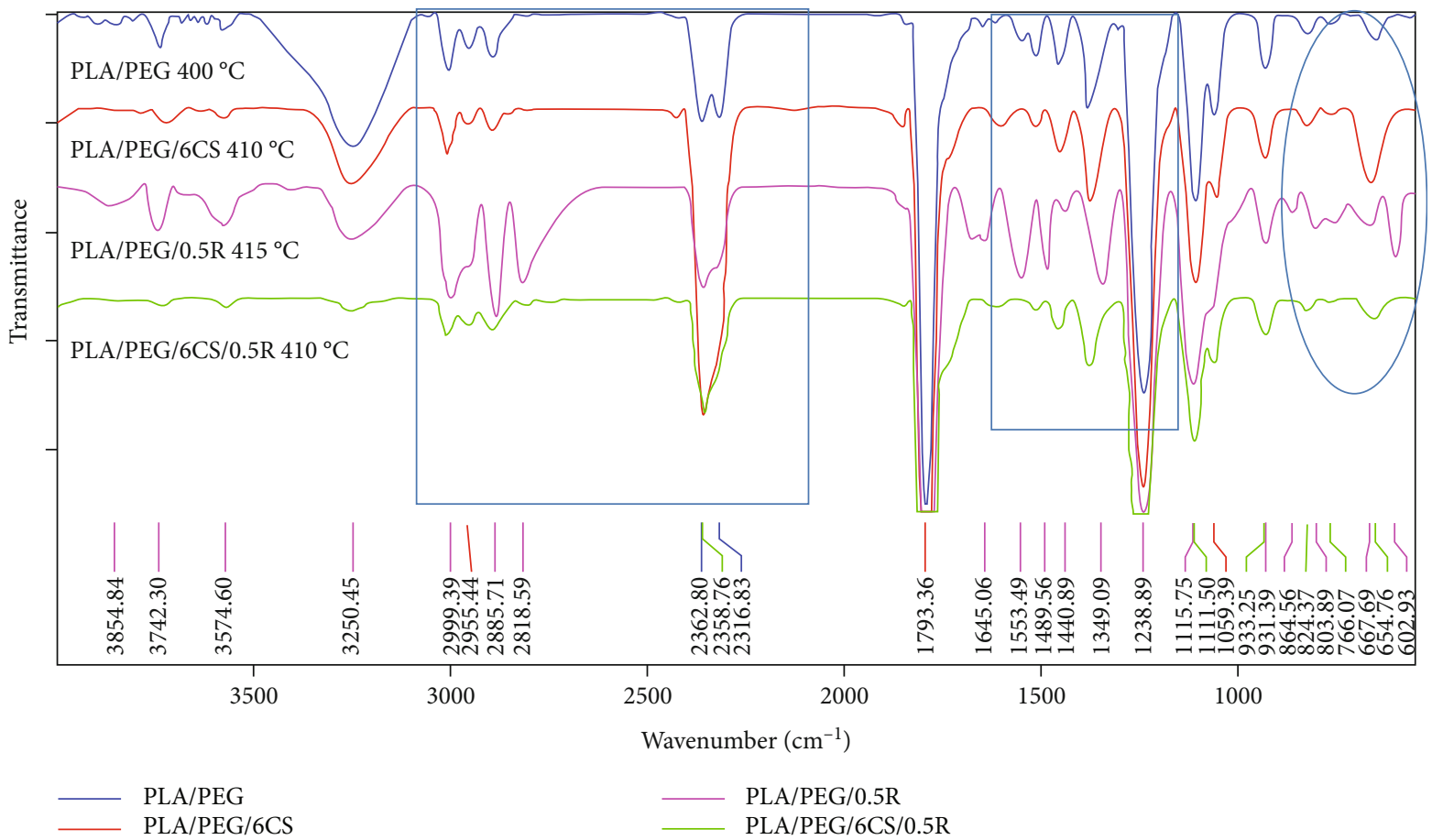

(b)

FIGURE 9: 2D FTIR spectra of the volatile decomposition products of PEG-plasticized PLA biocomposites at two GS temperatures of their evolution of $\sim 330-340^{\circ} \mathrm{C}$ (a) and $410^{\circ} \mathrm{C}(\mathrm{b})$.

light was observed for 13 days. Rosmarinic acid did not degrade either by itself or in the mixture, whereas carnosic acid was fairly stable than carnosol degradation. Carnosic acid by itself and in the mixture was quite stable. Rosmanol, epirosmanol, and epirosmanol ethyl ether major degradation products were also observed in HPLC chromatograms of carnosol and effect of temperature was also noticed during the formation of these degradation products. Rosmanol was 


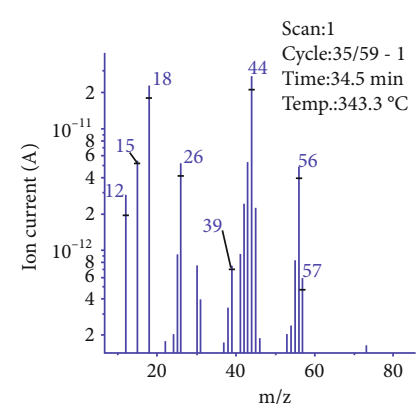

(a)

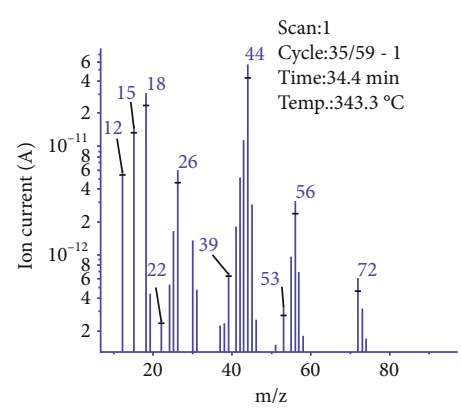

(a)

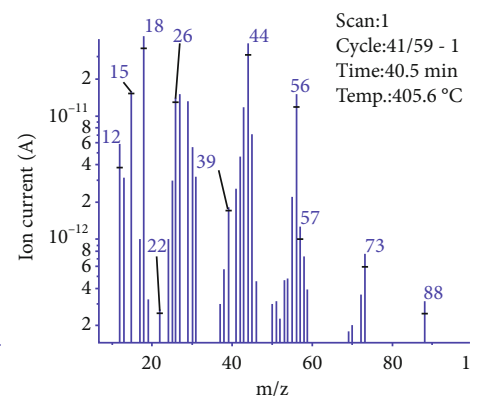

(b)

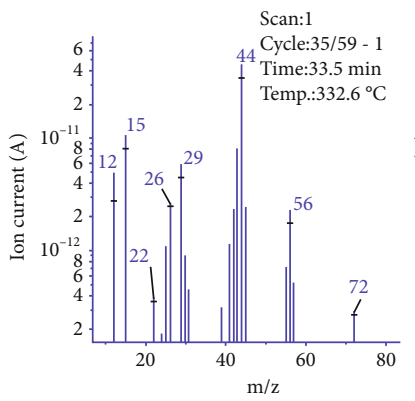

(a)

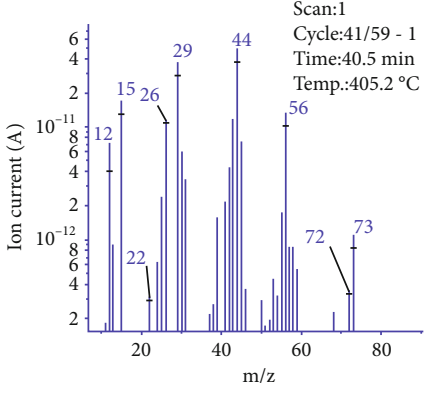

(b)

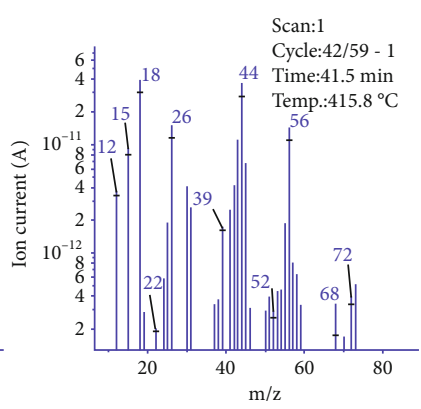

(b)

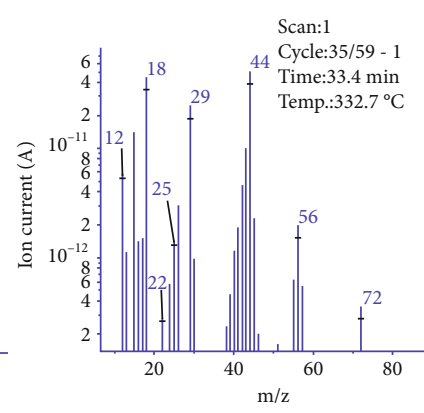

(a)

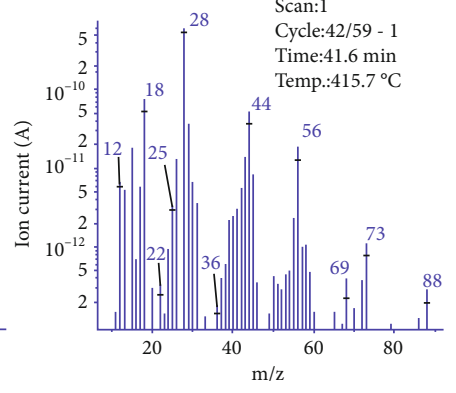

PLA/PEG/6CS/R

(b)

FIGURE 10: MS spectra corresponding to a maximum decomposition rate temperature of two steps in DTG curves: $\sim 330$-340 ${ }^{\circ} \mathrm{C}$ (a) and 400 $415^{\circ} \mathrm{C}(\mathrm{b})$.

present in the highest amount when stored at $-10^{\circ} \mathrm{C}$. Rosmadial and 11-ethoxy-rosmanol semiquinone also appeared as degradation products in carnosol HPLC chromatograms.

No toxicity or allergic responses were found for most of identified degradation products [89].

\section{Conclusion}

Thermal behavior of some multifunctional environmentally friendly materials exhibiting antimicrobial/antioxidant activities and biocompatibility, based on PEG-plasticized PLA/CS and rosemary extract (R), has been investigated. Differential scanning calorimetry, combined with other complex investigations such as chemiluminescence and coupled thermogravimetry/Fourier-transform infrared spectroscopy/mass spectroscopy methods, was applied both to test the thermal behavior and to establish the composition-property relationship for the developed biocomposites. It has been established that the addition of CS shifted the $T_{\mathrm{g}}$ to slightly higher values while the cold crystallization temperature of PLA-based biocomposites to lower temperatures showing that the CS can promote the crystallization of PLA. This is also proved by the increase of the crystallization degree of the biocomposites in respect with that of plasticized PLA. Melting temperature is not changed while melting heat takes higher values for biocomposites in respect with PLA/PEG blend. It has been evidenced by a chemiluminescence study that the rosemary ethanolic extract is a good stabilizer for thermoxidative degradation of PLA. The highest onset $\left(T_{\text {onset }}\right)$, maximum $\left(T_{\max }\right)$, and, respectively, GS temperature and decomposition temperatures corresponding to $10 \%\left(T_{10}\right)$ and $20 \%\left(T_{20}\right)$ mass loss are found for the PLA/PEG/6CS and PLA/PEG/CS/R biocomposites. The same biocomposites also show the highest values for apparent activation energy of decomposition. Therefore, the plasticized PLA/CS/R materials show good thermal properties and most of thermal degradation products are nontoxic being recommended as suitable for both medical and food packaging applications.

\section{Data Availability}

The data used to support the findings of this study are available from the corresponding author upon request.

\section{Additional Points}

Highlights. New plasticized PLA-based materials have been obtained by melt blending with chitosan and powdered rosemary ethanolic extract. The effect of natural additives on the thermal behavior of PEG-plasticized PLA was assessed. The thermal characteristics confirmed the good thermal performance of these biocomposites for application in biomedicine or food packaging field.

\section{Conflicts of Interest}

The authors declare that there is no conflict of interest regarding the publication of this paper.

\section{Acknowledgments}

The financial support of European Social Fund for Regional Development, Competitiveness Operational Programme 
Axis 1-Project "Petru Poni Institute of Macromolecular Chemistry-Interdisciplinary Pol for Smart Specialization through Research and Innovation and Technology Transfer in Bio(nano)polymeric Materials and (Eco)Technology," InoMatPol (ID P_36_570, Contract 142/10.10.2016, cod MySMIS: 107464), is gratefully acknowledged.

\section{References}

[1] L. Chen, X. Qiu, Z. Xie et al., "Poly(L-lactide)/starch blends compatibilized with poly(L-lactide)-g-starch copolymer," Carbohydrate Polymers, vol. 65, no. 1, pp. 75-80, 2006.

[2] M. A. Elsawy, K. H. Kim, J. W. Park, and A. Deep, "Hydrolytic degradation of polylactic acid (PLA) and its composites," November Renewable and Sustainable Energy Reviews, vol. 79, pp. 1346-1352, 2017.

[3] V. Taubner and R. Shishoo, "Influence of processing parameters on the degradation of poly(L-lactide) during extrusion," Journal of Applied Polymer Science, vol. 79, no. 12, pp. 21282135, 2001.

[4] M. C. Gupta and V. G. Deshmukh, "Thermal oxidative degradation of poly-lactic acid," Colloid \& Polymer Science, vol. 260, no. 3, pp. 308-311, 1982.

[5] S. H. Hyon, K. Jamshidi, and Y. Ikada, "Effects of residual monomer on the degradation of DL-lactide polymer," Polymer International, vol. 46, no. 3, pp. 196-202, 1998.

[6] H. Yu, N. Huang, C. Wang, and Z. Tang, "Modeling of poly(L-lactide) thermal degradation: theoretical prediction of molecular weight and polydispersity index," Journal of Applied Polymer Science, vol. 88, no. 11, pp. 2557-2562, 2003.

[7] M. R. Mitchell, R. E. Link, M.-H. Yang, and Y.-H. Lin, "Measurement and Simulation of Thermal Stability of poly(lactic acid) by thermogravimetric analysis," Journal of Testing and Evaluation, vol. 37, no. 4, p. 102271, 2009.

[8] S. Gogolewski, M. Jovanovic, S. M. Perren, J. G. Dillon, and M. K. Hughes, "The effect of melt-processing on the degradation of selected polyhydroxyacids: polylactides, polyhydroxybutyrate, and polyhydroxybutyrate-co-valerates," Polymer Degradation and Stability, vol. 40, no. 3, pp. 313-322, 1993.

[9] S. Saeidlou, M. A. Huneault, H. Li, and C. B. Park, "Poly(lactic acid) crystallization," Progress in Polymer Science, vol. 37, no. 12, pp. 1657-1677, 2012.

[10] M. Savaris, V. D. Santos, and R. N. Brandalise, "Influence of different sterilization processes on the properties of commercial poly(lactic acid)," Materials Science and Engineering: $C$, vol. 69, pp. 661-667, 2016.

[11] H. Tsuji and I. Fukui, "Enhanced thermal stability of poly(lactide)s in the melt by enantiomeric polymer blending," Polymer, vol. 44, no. 10, pp. 2891-2896, 2003.

[12] Z. Jing, X. Shi, and G. Zhang, "Competitive stereocomplexation and homocrystallization behaviors in the poly(lactide) blends of PLLA and PDLA-PEG-PDLA with controlled block length," Polymers, vol. 9, no. 12, p. 107, 2017.

[13] F.-L. Jin, R.-R. Hu, and S.-J. Park, "Improvement of thermal behaviors of biodegradable poly(lactic acid) polymer: a review," Composites Part B: Engineering, vol. 164, pp. 287296, 2019.

[14] R. M. Rasal, A. V. Janorkar, and D. E. Hirt, "Poly(lactic acid) modifications," Progress in Polymer Science, vol. 35, no. 3, pp. 338-356, 2010.
[15] A. Ruellan, V. Ducruet, and S. Domenek, "Plasticization of poly(lactide)," in Poly(lactic acid) Science and Technology: Processing, Properties, Additives and Applications, Polymer Chemistry Series No. 12, pp. 124-170, The Royal Society of Chemistry, 2015.

[16] M. Rapa, R. N. Darie-Niță, A. Irimia et al., "Comparative analysis of two bioplasticizers used to modulate the properties of PLA biocomposites," Materiale Plastice, vol. 54, no. 4, pp. 610-615, 2017.

[17] M. Râpă, R. N. Darie-Niță, E. Grosu et al., "Effect of plasticizers on melt processability and properties of PHB," Journal of Optoelectronics and Advanced Materials, vol. 17, no. 11-12, pp. 1778-1784, 2015.

[18] M. Rapa, R. N. Darie-Niță, and C. Vasile, "Influence of plasticizers over some physico-chemical properties of PLA," Materiale Plastice, vol. 54, no. 1, pp. 73-78, 2017.

[19] M. Râpă, C. Vasile, E. Grosu et al., PCT/RO2016 1000028/27.12.2016. PLA -based active and degradable biocomposites for food packaging, publication WO/2018/117885/ 28.06, International Application No.:PCT/RO2016/000028, 2018.

[20] M. Râpă, A. C. Mitelut, E. E. Tanase et al., "Influence of chitosan on mechanical, thermal, barrier and antimicrobial properties of PLA-biocomposites for food packaging," Composites Part B: Engineering, vol. 102, pp. 112-121, 2016.

[21] R. N. Darie-Niță, C. Vasile, A. Irimia, R. Lipşa, and M. Râpă, "Evaluation of some eco-friendly plasticizers for PLA films processing," Journal of Applied Polymer Science, vol. 133, no. 13,2016

[22] O. Martin and L. Avérous, "Poly(lactic acid): plasticization and properties of biodegradable multiphase systems," Polymer, vol. 42 , no. 14 , pp. 6209-6219, 2001.

[23] F. Croisier and C. Jérôme, "Chitosan-based biomaterials for tissue engineering," European Polymer Journal, vol. 49, no. 4, pp. 780-792, 2013.

[24] I. Wedmore, J. G. McManus, A. E. Pusateri, and J. B. Holcomb, "A special report on the chitosan-based hemostatic dressing: experience in current combat operations," The Journal of Trauma, vol. 60, no. 3, pp. 655-658, 2006.

[25] R. Darie-Niță, C. Vasile, E. Stoleru et al., "Evaluation of the rosemary extract effect on the properties of polylactic acidbased materials," Materials, vol. 11, no. 10, p. 1825, 2018.

[26] N. T. Maheshwari, Kansas State University, Manhattan Kansas, 2016, 1994, http://krex.k-state.edu/dspace/handle/ 2097/20596.

[27] A. Tomaino, F. Cimino, V. Zimbalatti et al., "Influence of heating on antioxidant activity and the chemical composition of some spice essential oils," Food Chemistry, vol. 89, no. 4, pp. 549-554, 2005.

[28] M. Khatun, S. Eguchi, T. Yamaguchi, H. Takamura, and T. Matoba, "Effect of thermal treatment on radicalscavenging activity of some spices," Food Science and Technology Research, vol. 12, no. 3, pp. 178-185, 2006.

[29] C. Vasile, E. Stoleru, R. N. Darie-Nița, R. P. Dumitriu, D. Pamfil, and L. Tarțau, "biocompatible materials based on plasticized Poly(lactic acid), chitosan and rosemary ethanolic Extract I. Effect of chitosan on the properties of plasticized Poly(lactic acid) materials," Polymers, vol. 11, no. 6, p. 941, 2019.

[30] T. Zaharescu, S. Jipa, W. Kappel, D. Artenie-Mariş, M. Mariş, and A. Mantsch, E-Polymers, vol. 1, p. 149, 2009, http://www e-polymers.org. 
[31] N. Troncoso, H. Sierra, L. Carvajal, P. Delpiano, and G. Gunther, "Fast high performance liquid chromatography and ultraviolet-visible quantification of principal phenolic antioxidants in fresh rosemary," Journal of Chromatography A, vol. 1100, no. 1, pp. 20-25, 2005.

[32] H.-J. Liu, C.-T. Hsieh, and D. S.-G. Hu, "Solute diffusion through degradable semicrystalline polyethylene glycol/poly(L-lactide) copolymers," Polymer Bulletin, vol. 32, no. 4, pp. 463-470, 1994.

[33] X. Liu, M. Dever, N. Fair, and R. S. Benson, "Thermal and mechanical properties of poly(lactic acid) and poly(ethylene/butylene succinate) blends," Journal of environmental polymer degradation, vol. 5, no. 4, pp. 225-235, 1997.

[34] H. E. Kissinger, "Reaction kinetics in differential thermal analysis," Analytical Chemistry, vol. 29, no. 11, pp. 1702-1706, 1957.

[35] P. Budrugeac and E. Segal, "Applicability of the Kissinger equation in thermal analysis," Journal of Thermal Analysis and Calorimetry, vol. 88, no. 3, pp. 703-707, 2007.

[36] J. P. Elder, "The general applicability of the Kissinger equation in thermal analysis," Journal of Thermal Analysis, vol. 30, no. 3, pp. 657-669, 1985.

[37] R. M. R. Wellen and E. L. Canedo, "On the Kissinger equation and the estimate of activation energies for non- isothermal cold crystallization of PET," Polymer Testing, vol. 40, pp. 3338, 2014.

[38] https://www.perkinelmer.com/lab-solutions/resources/docs/ APP_TgandMeltofPolyethylene.pdf.

[39] S. Jia, D. Yu, Y. Zhu, Z. Wang, L. Chen, and L. Fu, "Morphology, Crystallization and thermal behaviors of PLA-based composites: wonderful effects of hybrid GO/PEG via dynamic impregnating," Polymers, vol. 9, no. 12, pp. 528-535, 2017, https://www.mdpi.com/journal/polymers.

[40] N. T. T. Trang, N. T. Chinh, N. V. Giang et al., "Hydrolysis of green nanocomposites of poly(lactic acid) (PLA), chitosan (CS) and polyethylene glycol (PEG) in acid solution," Green Processing and Synthesis, vol. 5, no. 5, pp. 443-449, 2016.

[41] S. Kamthai and R. Magaraphan, "Thermal and mechanical properties of polylactic acid (PLA) and (CMCB) composite by adding isosorbide diesters," AIP Conference Proceedings, vol. 1664, article 060006, 2015.

[42] M. Bijarimi, S. Ahmad, R. Rasid, M. A. Khushairi, and M. Zakir, "Poly(lactic acid) / poly(ethylene glycol) blends: mechanical, thermal and morphological properties," AIP Conference Proceedings, vol. 1727, article 020002, 2016.

[43] J. Ahmed, N. Hiremath, and H. Jacob, “Antimicrobial, rheological, and thermal properties of plasticized polylactide films incorporated with essential oils to InhibitStaphylococcus aureusandCampylobacter jejuni," Journal of Food Science, vol. 81, no. 2, pp. E419-E429, 2016.

[44] M. Ramos, A. Jimenez, M. Peltzer, and M. C. Garrigos, "Development of novel nano-biocomposite antioxidant films based on poly (lactic acid) and thymol for active packaging," Food Chemistry, vol. 162, pp. 149-155, 2014.

[45] Y. Qin, J. Yang, and J. Xue, “Characterization of antimicrobial poly(lactic acid)/poly(trimethylene carbonate) films with cinnamaldehyde," Journal of Materials Science, vol. 50, no. 3, pp. 1150-1158, 2015.

[46] A. A. J. Kumar and V. Srinivasan, "Mechanical and thermal properties of chitosan filled poly lactic acid/basalt fiber hybrid composites," Journal of Advanced Microscopy Research, vol. 11, no. 1, pp. 23-30, 2016.

[47] J. Z. Xu, Z. J. Zhang, H. Xu, J. B. Chen, R. Ran, and Z. M. Li, "Highly enhanced crystallization kinetics of poly(l-lactic acid) by poly(ethylene glycol) grafted graphene oxide simultaneously as heterogeneous nucleation agent and chain mobility promoter," Macromolecules, vol. 48, no. 14, pp. 4891-4900, 2015.

[48] W. C. Lai, W. B. Liau, and T. T. Lin, "The effect of end groups of PEG on the crystallization behaviors of binary crystalline polymer blends PEG/PLLA," Polymer, vol. 45, no. 9, pp. 3073-3080, 2004.

[49] N. Kameno, S. Yamada, T. Amimoto, K. Amimoto, H. Ikeda, and N. Koga, "Thermal degradation of poly(lactic acid) oligomer: reaction mechanism and multistep kinetic behavior," Polymer Degradation and Stability, vol. 134, pp. 284-295, 2016.

[50] J. Glastrup, "Degradation of polyethylene glycol. A study of the reaction mechanism in a model molecule: tetraethylene glycol," Polymer Degradation and Stability, vol. 52, no. 3, pp. 217-222, 1996.

[51] T. Zaharescu, M. Râpă, and V. Marinescu, "Chemiluminescence kinetic analysis on the oxidative degradation of poly(lactic acid)," Journal of Thermal Analysis and Calorimetry, vol. 128, no. 1, pp. 185-191, 2017.

[52] R. Al-Itry, K. Lamnawar, and A. Maazouz, "Improvement of thermal stability, rheological and mechanical properties of PLA, PBAT and their blends by reactive extrusion with functionalized epoxy," Polymer Degradation and Stability, vol. 97, no. 10, pp. 1898-1914, 2012.

[53] Y. Fan, H. Nishida, Y. Shirai, Y. Tokiwa, and T. Endo, “Thermal degradation behaviour of poly(lactic acid) stereocomplex," Polymer Degradation and Stability, vol. 86, no. 2, pp. 197-208, 2004.

[54] D. J. Carlsson, C. J. B. Dobbin, and D. M. Wiles, "Direct observations of macroperoxyl radical propagation and termination by electron spin resonance and infrared spectroscopies," Macromolecules, vol. 18, no. 10, pp. 2092-2094, 1985.

[55] T. Zaharescu, M. Râpă, E.-M. Lungulescu, and N. Butoi, "Filler effect on the degradation of $\gamma$-processed PLA/vinyl POSS hybrid," Physical Chemistry, vol. 153, pp. 188-197, 2018.

[56] R. Dorati, I. Genta, L. Montanari et al., "The effect of $\gamma$-irradiation on PLGA/PEG microspheres containing ovalbumin," Journal of Controlled Release, vol. 107, no. 1, pp. 78-90, 2005.

[57] Q. Breche, G. Chagnon, G. Machado et al., "Mechanical behaviour's evolution of a PLA- b -PEG-b-PLA triblock copolymer during hydrolytic degradation," Journal of The Mechanical Behavior of Biomedical Materials, vol. 60, pp. 288-300, 2016.

[58] R. Scaffaro, A. Maio, F. Lopresti et al., "Synthesis and selfassembly of a PEGylated-graphene aerogel," Composites Science and Technology, vol. 128, pp. 193-200, 2016.

[59] M. Oliveira, E. Santos, A. Araújo, G. J. M. Fechine, A. V. Machado, and G. Botelho, "The role of shear and stabilizer on PLA degradation," Polymer Testing, vol. 51, pp. 109-116, 2016.

[60] D. Cam and M. Marucci, "Influence of residual monomers and metals on poly (L-lactide) thermal stability," Polymer, vol. 38, no. 8, pp. 1879-1884, 1997.

[61] F. D. Kopinke and K. Mackenzie, "Mechanistic aspects of the thermal degradation of poly(lactic acid) and poly $(\beta$-hydroxybutyric acid)," Journal of Analytical and Applied Pyrolysis, vol. 40-41, no. 40/41, pp. 43-53, 1997. 
[62] P. Nugroho, H. Mitomo, F. Yoshii, and T. Kume, "Degradation of poly(L-lactic acid)by $\gamma$-irradiation," Polymer Degradation and Stability, vol. 72, no. 2, pp. 337-343, 2001.

[63] G. Reich, "Ultrasound-induced degradation of PLA and PLGA during microsphere processing: influence of formulation variables," European Journal of Pharmaceutics and Biopharmaceutics, vol. 45, no. 2, pp. 165-171, 1998.

[64] G. Y. Lee, Thermal degradation of poly(lactic acid), Graduate Institute of Environmentally Polymeric Materials of KaoYuan University, Taiwan, ROC, 2006.

[65] F. D. Kopinke, M. Remmler, K. Mackenzie, M. Möder, and O. Wachsen, "Thermal decomposition of biodegradable polyesters-II. Poly(lactic acid)," Polymer Degradation and Stability, vol. 53, no. 3, pp. 329-342, 1996.

[66] B. Chieng, N. Ibrahim, Y. Then, and Y. Loo, "Epoxidized vegetable oils plasticized poly(lactic acid) biocomposites: mechanical, thermal and morphology properties," Molecules, vol. 19, no. 10, pp. 16024-16038, 2014, https://www.mdpi .com/journal/molecules.

[67] C. P. Chang, I.-C. Wang, and Y.-S. Perng, "Enhanced thermal behavior, mechanical properties and UV shielding of polylactic acid (PLA) composites reinforced with nanocrystalline cellulose and filled with nanosericite," Cellulose Chemistry and Technology, vol. 47, no. 1-2, pp. 111-123, 2013.

[68] E. Fortunati, I. Armentano, A. Iannoni, and J. M. Kenny, "Development and thermal behaviour of ternary PLA matrix composites," Polymer Degradation and Stability, vol. 95, no. 11, pp. 2200-2206, 2010.

[69] A. Y. Snegirev, V. A. Talalov, V. V. Stepanov, O. P. Korobeinichev, I. E. Gerasimov, and A. G. Shmakov, "Autocatalysis in thermal decomposition of polymers," Polymer Degradation and Stability, vol. 137, pp. 151-161, 2017.

[70] A. N. Ford Versypt, D. W. Pack, and R. D. Braatz, "Mathematical modeling of drug delivery from autocatalytically degradable PLGA microspheres-a review," Journal of Controlled Release, vol. 165, no. 1, pp. 29-37, 2013.

[71] I. C. McNeill and H. A. Leiper, "Degradation studies of some polyesters and polycarbonates- $1 \backslash$. Polylactide: General features of the degradation under programmed heating conditions," Polymer Degradation and Stability, vol. 11, no. 3, pp. 267-285, 1985.

[72] I. C. McNeill and H. A. Leiper, "Degradation studies of some polyesters and polycarbonates-2\. Polylactide: Degradation under isothermal conditions, thermal degradation mechanism and photolysis of the polymer," Polymer Degradation and Stability, vol. 11, no. 4, pp. 309-326, 1985.

[73] Y. Aoyagi, K. Yamashita, and Y. Doi, "Thermal degradation of poly[(R)-3-hydroxybutyrate], poly[E-caprolactone], and poly[(S)-lactide]," Polymer Degradation and Stability, vol. 76, no. 1, pp. 53-59, 2002.

[74] G. Sivalingam and G. Madras, "Thermal degradation of binary physical mixtures and copolymers of poly( $\varepsilon$-caprolactone), poly(D, L-lactide), poly(glycolide)," Polymer Degradation and Stability, vol. 84, no. 3, pp. 393-398, 2004.

[75] A. K. Pal and V. Katiyar, "Thermal degradation behaviour of nanoamphiphilic chitosan dispersed poly (lactic acid) bionanocomposite films," International Journal of Biological Macromolecules, vol. 95, pp. 1267-1279, 2017.

[76] C. M. Topala and L. D. Tataru, "ATR-FTIR study of thyme and rosemary oils extracted by supercritical carbon dioxide," Revista de Chimie, vol. 67, no. 5, pp. 842-846, 2016.
[77] https://www.cpp.edu/ psbeauchamp/pdf/spec_ir_nmr_ spectra_tables.pdf.

[78] H. Nishida, T. Mori, S. Hoshihara, Y. Fan, Y. Shirai, and T. Endo, "Effect of tin on poly(l-lactic acid) pyrolysis," Polymer Degradation and Stability, vol. 81, no. 3, pp. 515-523, 2003.

[79] S. Tsuge, H. Ohtani, and C. Watanabe, Pyrolysis-GC/MS Data Book of Synthetic Polymers: Pyrograms, Thermograms and MS of Pyrolyzates, vol. 420, Elsevier, 2011, https://books.google.ro/ books? id=mbtybfqbEs $8 \mathrm{C} \&$ printsec $=$ frontcover $\& \mathrm{hl}=$ ro\&source $=$ gbs_ge_summary_r $\&$ cad $=0 \# \mathrm{v}=$ onepage $\& \mathrm{q} \& \mathrm{f}=$ false.

[80] H. Lin, L. Han, and L. Dong, "Thermal degradation behavior and gas phase flame-retardant mechanism of polylactide/PCPP blends," Journal of Applied Polymer Science, vol. 131, no. 13, p. 40480, 2014.

[81] P.-Z. Hong, S.-D. Li, C.-Y. Ou, C.-P. Li, L. Yang, and C.H. Zhang, "Thermogravimetric analysis of chitosan," Journal of Applied Polymer Science, vol. 105, no. 2, pp. 547-551, 2007.

[82] I. Corazzari, R. Nisticò, F. Turci et al., "Advanced physicochemical characterization of chitosan by means of TGA coupled on-line with FTIR and GCMS: thermal degradation and water adsorption capacity," Polymer Degradation and Stability, vol. 112, pp. 1-9, 2015.

[83] M. A. Diab, A. Z. El-Sonbati, M. M. Al-Halawany, and D. M. D. Bader, "Thermal stability and degradation of chitosan modified by cinnamic acid," Open Journal of Polymer Chemistry, vol. 2, no. 1, pp. 14-20, 2012.

[84] M. A. Diab, A. Z. El-Sonbati, and D. M. D. Bader, "Thermal stability and degradation of chitosan modified by benzophenone," Spectrochimica Acta. Part A, Molecular and Biomolecular Spectroscopy, vol. 79, no. 5, pp. 1057-1062, 2011.

[85] J. Mattai and E. R. Hayes, "Characterization of chitosan by pyrolysis-mass spectrometry," Journal of Analytical and Applied Pyrolysis, vol. 3, no. 4, pp. 327-334, 1982.

[86] M. Islamcevic-Razborsek, D. Brodnjak Voncina, V. Dolecek, and E. Voncina, "Determination of major phenolic acids, phenolic diterpenes and triterpenes in rosemary (Rosmarinus officinalis L.) by gas chromatography and mass spectrometry," Acta Chimica Slovenica, vol. 54, pp. 60-67, 2007.

[87] J. Damasius, P. R. Venskutonis, V. Kaskoniene, and A. Maruska, "Fast screening of the main phenolic acids with antioxidant properties in common spices using on-line HPLC/UV/DPPH radical scavenging assay," Analytical Methods, vol. 6, no. 8, p. 2774, 2014.

[88] Y. Zhang, J. P. Smuts, E. Dodbiba, R. Rangarajan, J. C. Lang, and D. W. Armstrong, "Degradation study of carnosic acid, carnosol, rosmarinic acid, and rosemary extract (Rosmarinus officinalisL.) assessed using HPLC," Journal of Agricultural and Food Chemistry, vol. 60, no. 36, pp. 9305-9314, 2012.

[89] M. T. Cronin, J. Madden, D. Roberts, and S. Enoch, Chemical toxicity prediction: category formation and read-across, Royal Society of Chemistry, 2013. 